Work Papers of the Summer

Institute of Linguistics, University

of North Dakota Session

\title{
From meaning to text: Semantic representation in the Meaning- Text linguistic theory and a new type of monolingual dictionary
}

Igor A. Mel'čuk

University of Montreal

How does access to this work benefit you? Let us know!

Follow this and additional works at: https://commons.und.edu/sil-work-papers

Part of the Linguistics Commons

\footnotetext{
Recommended Citation

Mel'čuk, Igor A. (1987) "From meaning to text: Semantic representation in the Meaning-Text linguistic theory and a new type of monolingual dictionary," Work Papers of the Summer Institute of Linguistics, University of North Dakota Session: Vol. 31, Article 4.

DOI: 10.31356/silwp.vol31.04

Available at: https://commons.und.edu/sil-work-papers/vol31/iss1/4

This Article is brought to you for free and open access by UND Scholarly Commons. It has been accepted for inclusion in Work Papers of the Summer Institute of Linguistics, University of North Dakota Session by an authorized editor of UND Scholarly Commons. For more information, please contact und.commons@library.und.edu.
} 
FROA MEANING TO TEXT:

Semantic Representation in the Meaning-Text Linguistic Theory and a New Type of Monolingual Dictionary

Igor A. Mel'Cuk

University of Montreal

1 Introduction

2 Outline of the Meaning-Text Theory

2.1 Main postulates and general characteristics

2.2 Semantic representation in the Meaning-Text Theory

3 The Explanatory Combinatorial Dictionary as a crucial

component of a Meaning-Text model

3.1 General characteristics

3.2 Structure of an ECD entry

3.2.1 Semantic zone

3.2.2 Syntactic zone

3.2.3 Lexical cooccurrence zone

Appendix A: List of Lexical Functions

Appendix B: three sample dictionary entries

\section{Introduction}

We use language primarily to express meanings. And to communicate, of course, but "sprachlich"1 communication boils down to an exchange of meanings expressed in and extracted from "sprachlich" messages). This is an obvious truth or, rather, a commonplace fact that no one in the linguistic profession has ever tried to call into question. All linguistic schools include in their respective credos strong statements concerning the crucial role of meaning and its expression in human language and, consequently, in linguistics. Thus half a century ago Leonard Bloomfield wrote: "In human speech, different sounds have different meanings. To study this coordination of certain sounds with certain meanings is to study language" (1933: 27). More recently, the same tenet has been vigorously restated, by (among others) Noam Chomsky: "A generative grammar ... is a system of rules that relate signals to semantic interpretations of these signals" (1966: 12). "The grammar of a language ... establishes a certain relation between sound and meaning" (1968: 116); etc. For the last ten years general interest in meaning and in the linguistic discipline dealing with meaning, i.e. semantics, has witnessed considerable growth.

Nevertheless, semantics today still remains an underdeveloped field. Meaning, which is de jure recognized as an important element of language, still is de facto, if not ignored, then frequently avoided or at least not dealt with as directly and systematically as it should be. Let us mention, for instance, Testen et al. 1984 - a volume called 
Lexical Semantics and representing one of the most recent publications in the field. The volume contains many interesting papers, and is full of astute remarks and insightful discussions of different semantic problems, but, curiously enough, in spite of its title, it does not offer descriptions, or even attempts at descriptions, of actual lexical meanings. This is quite typical of the approach of modern linguistics to semantics: First, most linguists concentrate on abstract questions having a strong logical flavor (quantification, logical connectives, referentiality, pragmatic functions of discourse, etc.), while consistently shunning the description of genuine "sprachlich" meanings, lexical or grammatical. Second, to the best of my knowledge, there is, in the mainstream of modern linguistics, no integrated theory of language that would consistently proceed from meaning. There is, at least, one obvious exception: the work of A. Wierzbicka proposes, develops and substantiates such a theory (cf. below). To discuss the reasons for this state of affairs would be out of place; suffice it to state that it justifies our expounding here a different approach to natural language, namely, the Meaning-Text Theory.

The Meaning-Text Theory (MTT) is not simply another of numerous linguistic theories, which proliferate to such an extent nowadays that there are almost as many theories as there are practicing linguists. The MTT is truly different in that it puts quite a new emphasis on "sprachlich" meaning, taking it as a cornerstone of language description as a whole; accordingly, semantics is declared and, most importantly, actually treated as the central linguistic discipline (which, among other things, underlies syntax and morphology).

The Meaning-Text Theory is by no means a novelty. It was launched in 1965, in Moscow, by A. Zholkovsky (now at the University of Southern California) and the present author: Žolkovskij and Mel'cuk 1965. Later, we were joined by Ju. D. Apresjan. Since that time, the MTT has been developing over the past 20 years (see Mel'ruk 1981 and Nakhimovsky 1983). However, the MTT still lacks an easily available and sufficiently detailed presentation in English, a gap which this paper tries to fill, at least in part, by outlining the two following topics:

(i) General structure of the MTT (with special attention to its semantic chapter) (Sect. 2).

(ii) A new type of monolingual dictionary, or lexicon, which according to the MTT constitutes the central part of the semantic component of any full-fledged "sprachlich" model (Sect. 3).

The character of our exposition forces us to ban references, including the most relevant ones. (Only a few are quoted, where they were judged necessary in order to identify the background of the MTT.) 


\section{Outline of the Meaning-Text Theory}

\subsection{Main Postulates and General Characteristics}

The basic idea underlying the Meaning-Text Theory is as follows. Any speech act is believed to consist of three major components:

(a) A CONTENT to be communicated by "sprachlich" signals; it will be called meaning.

(b) A complex SIGNAL, or SIGNALS (observable physical phenomena), used to communicate the content in question; this signal will be called text.

(c) A CORRESPONDENCE between the meaning and the text; it will be called mapping.

We will shortly make the concepts of meaning and text more precise, but before we do so we need to emphasize the following three important points concerning our tripartite division of a speech act.

First, we presuppose the discrete character of both meanings and texts. That is, we postulate that we can distinguish meanings and count them; likewise for texts. Meanings and, mutatis mutandis, texts are for us formal objects specifiable by a logical device (for instance, by a generative grammar). This is more or less accepted with respect to texts but seems to be rather unusual as applied to meanings.

Second, the set of possible speech acts is open: there is an infinite number of meanings and texts in every natural language. However, the mapping between meanings and texts is finite, i.e., it can be fully represented by a finite number of correspondence rules (even though this number is very large). This is the case since an arbitrary meaning, as well as an arbitrary text, can be, generally speaking, broken down into simpler meanings, viz. simpler texts, so that ultimate correspondences can be established between elementary meanings and elementary texts, the number of these entities being finite.

Third, there is no one-to-one correspondence between meanings and texts: one meaning can be expressed by quite a few texts (synonymy), and a text can express several meanings (homonymy/polysemy - or ambiguity).

The above-stated may be symbolized as in (1), which is the main postulate of the Meaning-Text Theory:

(1) Postulate 1

$$
\text { MEANING } \left.\left._{i}\right\} \quad \begin{array}{c}
\text { language } \\
\langle=\Rightarrow
\end{array} \operatorname{TEXT}_{j}\right\} \mid 0<i, j<\infty
$$


In the MTT, then, a natural language is viewed as a many-to-many mapping between an infinite set of meanings and an infinite set of texts.

Let it be emphasized and re-emphasized that the words meaning and text are to be taken, within the present framework, as technical terms, free of the many connotations they have in every-day English or in other terminological systems. Thus, as far as meaning is concerned, three important properties of our approach must be constantly borne in mind:

(1) We deal only with strictly "sprachlich" meaning, i.e. with the information which can be extracted from an utterance solely on the basis of purely "sprachlich" knowledge, without any reference to the context and/or extralinguistic environment (roughly, without any encyclopedic knowledge about the universe). Our "meaning" is the shallowest, absolutely literal meaning of utterances. Suppose a girl on a date says to her shy partner, "Oh, I'm cold!", in order to incite him to embrace her; for the MTT, the meaning of her utterance is still 'I'm cold' and by no means 'Go ahead and embrace me!' When I tell you that John has applied for a scholarship and you react by asking me, "What do you mean?", you are after quite a different meaning from what the MTT tries to describe. A meaning in the MTT is simply the invariant of a set of all utterances that are paraphrases of each other. Or, to put it differently, meaning is the canonical invariant of synonymous utterances (see below). Therefore, such things as truth, incoherence or absurdity are of no relevance to us: these properties concern the relationship between "sprachlich" meaning and something else (= the universe), while the task of the MTT is precisely to avoid discussing anything that is beyond language.

(11) Meaning is taken to be directly accessible to speakers much like the sounds of their language. This is not to be construed as implying that any speaker is able to correctly analyze or explain any given meaning; such is by no means the case. But every speaker knows (though perhaps subconsciously) what he wants to say, even if he does not understand the deeper meaning of his words (this last circumstance should not bother us). Therefore meaning is open to direct introspection; for a trained linguist describing his mother tongue, meaning belongs to the data.

(iii) Although we talk of meaning, the MTT deals, in actual fact, with formal representations of meanings, called Sem(antic) $\mathrm{R}$ (epresentations). Meanings do have an objective existence of their own - as certain neurophysiological events in the speaker's brain. But once again, this is of no relevance for us. When we write $\left\{\right.$ MEANING $\left._{1}\right\}$, we mean $\left\{\operatorname{Sem} R_{1}\right\}$. These representations, invented and developed by the linguist, are our only semantic reality within the limits of the MTT, of course.

Texts possess three similar properties as well. 
(i') The term text should by no means be understood as 'coherent

text' or 'discourse', $i . e$. in the sense of the so-called text grammar. Our text is any linguistically, valid segment of speech; it can be the signifier (Lat. signans, Fr. signifiant) of a morph, a lexeme, a phrase, etc., including whole volumes.

(i1') Texts are directly accessible to the speaker, in the sense that he is able to tell a well-formed text in his language from an ill-formed or questionable one.

(iii') We deal with representations of texts only, not with actual texts (which consist of physical phenomena). Saying $\left\{\operatorname{TEXT}_{j}\right\}$, we mean $\{$ Phon(etic) R(epresentation) $j\}$, and only PhonR's are the object of our study.

Following the statements (i)-(iii) and ( $\left.i^{\prime}\right)-($ iii'), we can rewrite (1) as a more precise formulation, namely (2):

$$
\left\{\text { SemR }_{i}\right\} \stackrel{\text { language }}{\Longleftrightarrow==\Rightarrow}\left\{\text { PhonR }_{j}\right\} \mid 0<i, j<\infty
$$

What has been said so far allows us to draw an important conclusion. Given that we have to deal with representations of meanings and texts, our first and foremost task should be to develop formal languages to represent them. In slightly different words, the first thing we need in order to talk about natural language in a scientific way, so that all our statements are explicit and unambiguous, is a semantic transcription and a phonetic/phonemic transcription. Until we can formally present meanings and texts of a natural language we cannot, strictly speaking, discuss it.

Now, phonetic/phonemic transcriptions are readily available; where they are not, methods for developing them are familiar, and necessary skills and know-how are at hand. With meanings, however, the situation is different -- quite simply, it is disastrous. No serious efforts have been made in mainstream linguistics to develop semantic transcriptions; not even one artificial semantic (meta)language for one natural language has been proposed, as far as we know, in major linguistic schools. There are, to be sure, several developments that seem to contradict the last statement: take, for example, the insightful and promising work of A. Wierzbicka ( 1972 and 1980, to name only two of her many pioneering studies). But in spite of its interest and availability, Wierzbicka's research (as well as a number of similar attempts) remains little-known and, in a sense, marginal. Modern linguistics, as a whole, has not yet made semantic language its main concern. In sharp contrast, the MTT lays heavy emphasis on meaning representation, i.e. on Sem $R$ and, therefore, on a semantic language. In our opinion, such a language is a sine qua non of today's science of language. Later on, we will discuss 
the semantic language, i.e. the language of Sem $R$ used in the MTT, in more detail.

Now let us make the next important point. While meanings and texts (of a language) are immediately accessible to the linguist, rules that correlate them (e.g. the mapping $"\langle==>"$ in (1) and (2)) are not. Thus we linguists face the classical "black box" situation: we are in front of a running device (natural language) whose inputs and outputs are perceptible and controllable but whose inner structure, the circuits linking inputs with outputs, is totally hidden from us. "Sprachlich" rules mapping meanings onto texts and vice versa are electronically/chemically encoded in the speaker's brain, yet we cannot open skulls to find out about them. The only option we have can be expressed by the following:

\section{Postulate 2}

A natural language, viewed as a many-to-many mapping between two infinite sets (that of meanings and that of texts), can be described only by a Cybernetical, or Functional, Model.

A functional model of a device (phenomenon, event) $X$ is a logical device, or a finite set of formal rules, which simulates as closely as possible the behavior of $X$. In our case, $X$ is human language, and therefore our model should simulate the "sprachlich" behavior of humans -- in other words, it should establish correspondences between meanings and texts. It is such models that we call Meaning-Text Models (MTM). Strictly speaking, an MTM for language $£$ is a system of formal rules which associates with a given SemR of $£$, all the PhonR's that, in the judgment of $\AA^{\prime} s$ speakers, can carry the corresponding meaning, and vice versa, which associates with a given PhonR of $£$ all the possible SemR's -- all meanings that this text can have. Thus our second task should be to develop Meaning-Text models of languages. (Of course, this task is closely related to the first one, that of developing formal languages for linguistic representations in the first place -- for the SemR.) We can say that the Meaning-Text Theory is a theory for building MTM's.

Note that a complete Meaning-Text model should be a "dynamic" device in the sense that for a given SemR, it should actually produce the set of corresponding PhonR's. However, it seems natural to distinguish, within an MTM, two submodels: 1) the system of purely "sprachlich" rules which specify the correspondence between meanings and texts, and 2) the system of procedural rules which specify the process leading from a SemR to the PhonR's (or vice versa) - based on "sprachlich" rules, i.e. on the first system. The second system is by no means specific to linguistics. It includes rules that, using factual knowledge supplied by the first system, compute the best way (or one of the best possible ways) to construct the necessary PhonR for a given SemR (and to construct the necessary SemR for a given PhonR); the same type of procedural rules are needed whenever stored knowledge has to be 
used for the solution of any problem. Therefore, in all our deliberations, we will not concern ourselves with the second system of rules. Thus an MTM is considered and presented only in its strictly "sprachlich"/linguistic "static" aspects. This means, among other things, that it appears as a Static system of correspondences between elementary meanings and elementary texts, to the complete exclusion of all elements of procedure. Two important remarks are needed in this regard.

First, an MTM is by no means a generative or, for that matter, transformational device: it is equative (or, if you like, translative). It does not seek to generate (enumerate, specify) the set of all (and only) grammatical or meaningful texts, nor does it transform certain "sprachlich" entities into other entities. It simply states which SemR's match which PhonR's in accordance with native speakers' intuition.

Second, an MTM does not admit linear order as a formal means among its tools. To be sure, linear order is an important expressive means of natural languages and, as such, it has to be accounted for in the rules and the representations used by the model. However, "sprachlich" order should not be reflected simply by ordering the elements of the MTM. Thus MTM rules should be unordered and all relevant information about language should be explicitly represented by symbols and configurations thereof. Likewise, linear order is never admitted to express any "sprachlich" relations in the semantic or syntactic representations of utterances. Once again, all relations should be denoted by appropriate symbols. (Cf. Sanders 1972.)

We have mentioned above that the correspondence between meanings and texts is many-to-many. For a fairly complex meaning, hundreds of thousands of (nearly) synonymous texts can be constructed. Thus, example (4)

The Food and Drug Administration has seriously cautioned expectant mothers to avoid one of life's simple pleasures: a cup of coffee.

has more than 200,000 paraphrases (Mel'cuk 1981: 31-32). Similarly, a text may have several meanings (i.e. have distinct readings). The extremely involved character of the Meaning-Text correspondence makes it practically impossible to write its rules directly from meanings to texts. It turns out that for a better perspicuity and surveyability, the correspondence between meanings and texts must be broken down into simpler components. This entails the following:

\section{(5) Postulate 3}

To describe the correspondence $\left\{\right.$ SemR $\left._{i}\right\} \Leftrightarrow==\left\{\operatorname{PhonR}_{j}\right\}$, TWO INTERMEDIATE LEVELS of utterance representation are introduced: Synt(actic) R(epresentation) and 
Morph(ological) R(epresentation).

Therefore, (2) can now be rewritten, in a more developed form, as (6):

(6)

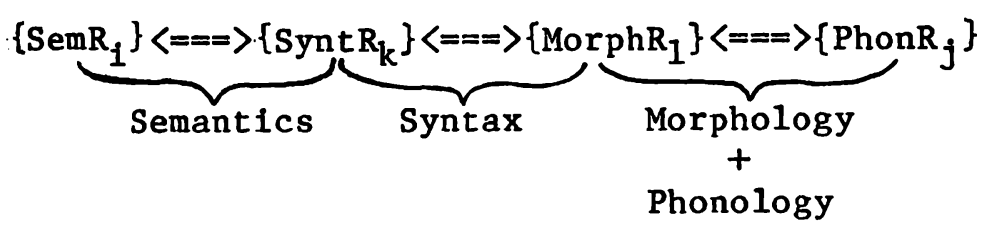

The SyntR and MorphR are centered, respectively, around the sentence and the word. Because of the obvious space constraints, we will not touch here upon such important properties of the SyntR and the MorphR as their division into deep and surface sublevels, the formalisms used, etc. We will limit ourselves to insisting on the stratificational, or multistratal, character of the proposed model (cf. Lamb 1966 and Sgall 1967). A Meaning-Text "sprachlich"/linguistic model consists, as shown in (6), of three major components, which form, so to speak, a production chain:

Semantics establishes the correspondence between the infinite set of SemR's and the infinite set of SyntR's;

Syntax establishes the correspondence between the SyntR's and the MorphR's;

Morphology + Phonology establish the correspondence between the MorphR's and the PhonR's.

In this presentation, we will be concerned exclusively with the semantic component of an MTM.

Note that in principle the correspondence $" \angle=\Rightarrow "$ is bidirectional: an MTM should be able to go both from meanings to texts (= speech production) and from texts to meanings (= speech understanding). Logically, both directions are, of course, equivalent, and both correspond to actually observable processes. Linguistically, however, they are not equivalent; natural language gives a more prominent place to the speaker than to the addressee:

(i) The speaker can speak (or write) even without an explicit addressee (to himself, to God, to posterity), while an addressee is inconceivable without an explicit speaker.

(ii) Reference to, or value judgments by, the speaker (rather than by the addressee) are included in the meaning of a host of "sprachlich" units: shifters (like here = 'where the speaker is'), speaker-oriented verbs like come vs. 
go, performative verbs, all affective and derogatory terms, and many others, without mentioning the cases of empathy (the speaker identifying himself with a character presented in his utterance), prepositional choices ( $X$ in front of $Y$ as opposed to $Y$ behind $X$, as a function of where the speaker mentally places himself), etc.

(1ii) Most important, the speaker knows perfectly well what he is going to say; his only problem, when he starts from a given meaning, is to find an appropriate "sprachlich" form (= text) to convey this meaning. His activity qua speaker is a purely "sprachlich" one. The addressee, on the other hand, has no previous knowledge of the meaning he is supposed to extract from the utterance. He has to use his logic, his general abilities to infer and guess, his knowledge of the world, etc. - in addition to his "sprachlich" skills proper. The addressee's activity qua addressee is not purely "sprachlich": it includes, to a considerable degree, many non-"sprachlich" operations, with the result that "sprachlich" operations occupy in it a rather modest place. 2

Consequent1y, the viewpoint of the speaker is by far the more advantageous for linguists. Describing language as a system for EXPRESSING meanings and not the other way around, we can concentrate on genuine "sprachlich" phenomena, thus avoiding involvement with problems of rule ordering and application, modalities of processing, encyclopedic understanding, and the like, which are absolutely irrelevant to linguistics. Let it be emphasized that certain "sprachlich" phenomena can be properly recognized and systematically studied only if considered in the direction from meanings to texts. Thus the following oppositions do not represent any interesting problem from the viewpoint of the addressee :

7) a. strong warning vs. considerable attention $\langle *$ considerable warning, *strong attention〉;

b. They differ widely vs. They miss her acutely $\langle *$ differ acutely, *miss widely〉;

c. much/widely/greatly publicized vs. heavily settled [area] <*heavily publicized,

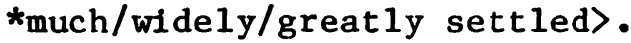

A listener or a reader easily understands the expressions in (7) and misses the interesting fact that the boldfaced lexemes express one and the same meaning, namely 'very', and are (complementarily) distributed according to the lexeme modifled. In fact, these lexemes are values of 
what is called the lexical function Magn. (The term Magn is from Lat. magnus 'great, big'.)

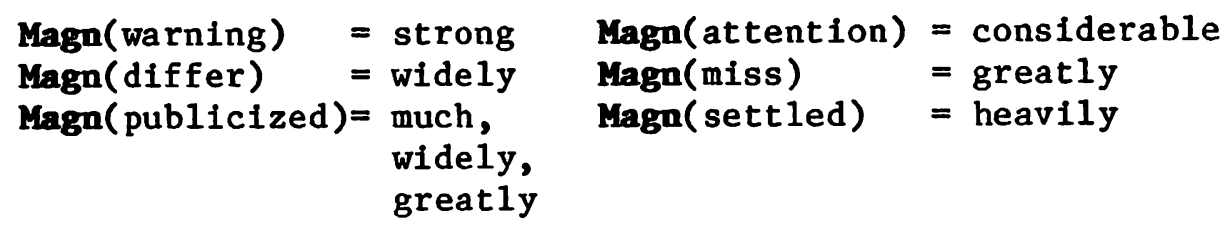

To discover that natural languages feature a limited number of very abstract and general meanings such that any one of these has numerous expressions distributed as shown above, one needs to look at language from the speaker's viewpoint. (Cf. the discussion about lexical functions, Sect. 3.2 .3 and a list of lexical functions, Appendix A.)

Therefore, in sharp contrast with most linguistic schools (traditional grammar, European and American structuralism, transformational grammar and its various outgrowths), the Meaning-Text Theory insists on the meaning-to-text direction in linguistic research, as well as in linguistic description.

To sum up: The Meaning-Text Theory aims at developing Meaning-Text models of natural languages. An MTM is taken to be a system of rules which establish correspondences between semantic and phonetic representations of utterances, the SemR's being written in a special semantic language, devised by the researcher. This is a multilevel, or multicomponent, system, with a semantic component responsible for the correspondence between semantic and syntactic representations: the semantic component "translates" SemR's into SyntR's (and vice versa). Last, but not least, the direction of research and description is that of production: from meanings to texts.

\subsection{Senantic Representation in the Meaning-Text Theory}

In conformity with the goal of this paper, we will now try to throw light on the concept of semantic representation.

Let us begin with an example. In Toronto's The Globe and Mail (Aug. 5, 1985, N6) we find the following title:

The death of 1ibido.

This is a short editorial, claiming that watching situation comedies on American TV has a pernicious effect on the viewer's sexual drive. The meaning of this title is clear; how can we represent it? Well, Iibido means (roughly) 'urge ${ }^{2}$ to copulate' (superscripts and numbers after words in our semantic descriptions refer to intended senses in Longman Dictionary of Contemporary English). 'Urge' [noun] is by necessity someone's urge; in this context, an indefinite group of people is meant: 'people 1'. Then, taking 'urge' and 'copulate' to be two-place predicates $^{3}$, we can write: 
(10)

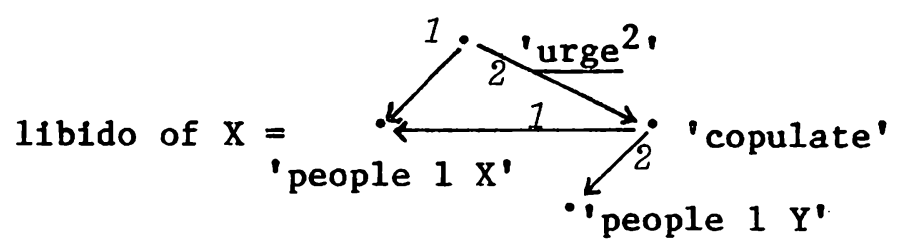

Or, to express it in prose,

(10') libido of $X={ }^{\prime}$ urge $^{2}$ of people $1 X$ to copulate with people $1 \mathrm{Y}^{\prime}$

The noun 'death' is used in (9) metaphorically, and means 'event 1 consisting in that $X$ ceases to exist $1^{\prime}$. In our formalism, then, we have (11):

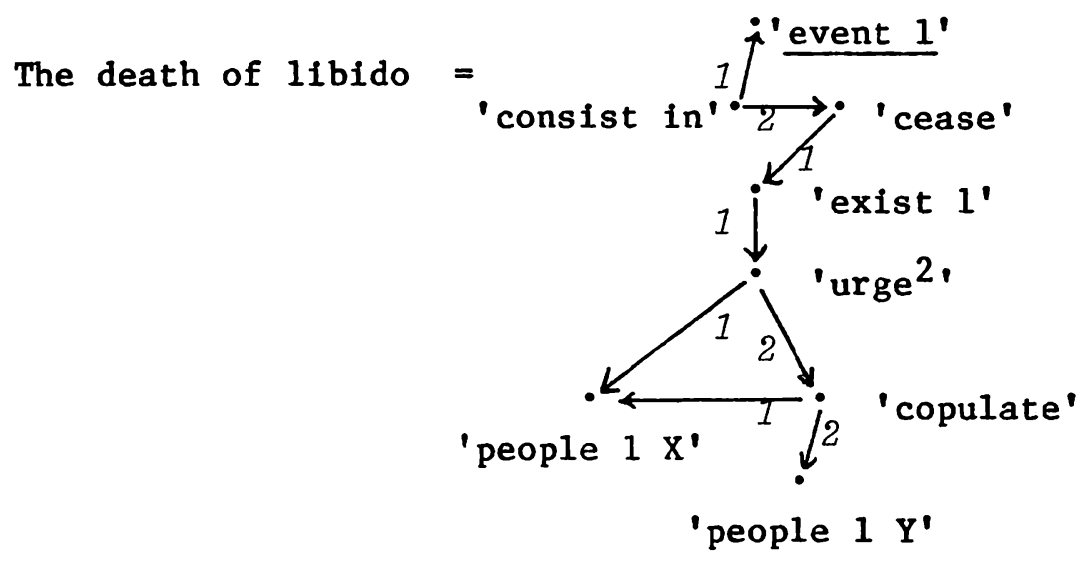

Numbers assigned to arrows in diagrams of (10) and (11) identify different arguments of the same predicate, underlining singles out the main component.

We believe that (11) represents the "sprachlich" meaning of the phrase the death of 11bido quite well. Two qualifications seem, however, to be in order.

First, while the expressions in single quotes in (10) and (11) look like English words, they are NOT English words -- rather, they are handy designations of specific senses of the corresponding English words, which, like almost all English words, are polysemous. To disambiguate them, we are using sense numbers borrowed from the Longman Dictionary, as indicated above. (For our illustrative purposes, it could be any other dictionary.) A word taken in one well-specified sense is called a lexeme. Then, the expressions in single quotes are semantic units, or senemes, notated with English lexemes. These sememes do not feature syntactic and morphological properties typical of English lexemes that represent them. They are indeed units of meaning.

Second, one might ask the legitimate question about the meaning of 
sememes themselves. For example, what does cease mean? In this case, the answer is simple:

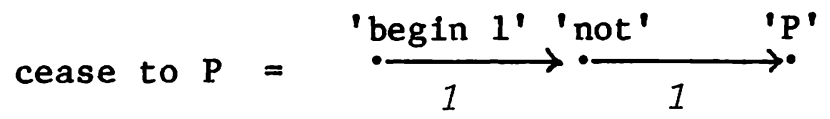

[John ceased to work = 'John began not to work']

But then, what is "begin 1"? The answer is still at hand:

$$
\text { begin } 1 \text { to } \begin{aligned}
P= & \text { at moment } t_{0}, P \text { does not exist } 1 \text {; } \\
& \text { at moment } t_{1}, P \text { exists } 1 \text {; } \\
& t_{1}>t_{0} \cdot
\end{aligned}
$$

However, things do not always go as smoothly as this. What does exist 1 mean? And moment 1? And not? For the time being, I cannot answer.

I do not imply that these terms cannot be explained or that their meaning cannot be described at all. It can, but maybe NOT IN "SPRACHLICH" TERMS. From the viewpoint of strictly "sprachlich" meaning, these sememes could be elementary or indecomposable: they are then semantic primitives. (Cf. 13 semantic primitives postulated by $A$. Wierzbicka: 1972 and $1980 .{ }^{4}$ )

Now we can proceed to specify the formal language, or semantic metalanguage, in which semantic representations within the MTT framework can be written. (To simplify the presentation, we will not consider the communicative organization of meaning, 1.e. contrasts of topic vs. comment, given vs. new, etc.)

Like any other formal language, the semantic language of the MTT is a pair of sets: a finite set of elements called alphabet (or lexicon) and a finite set of expressions called rules; there are formation rules, which specify we11-formed configurations of elements, and transformation rules, which specify equivalences between well-formed configurations. Let us take these components of the semantic language in turn:

An expression in the semantic language, i.e. a Sem(antic) $\mathrm{R}$ (epresentation), is, formally speaking, a completely labeled network: a connected oriented graph whose vertices, or nodes, are labeled with sememes and whose arcs, or branches, are labeled with arbitrary distinctive symbols. (We will use Arabic numbers; the purpose of using them is, as indicated above, to distinguish different arguments of the same predicate, cf. below). 5

The alphabet of the semantic language in question includes:

(a) A tiny list of formal elements (used to construct networks): vertices, represented by points; arcs, represented by arrows; and a 
small set of natural numbers as distinguishers, appearing as labels on arcs.

(b) A huge list of sememes (several million, generally speaking): each sememe corresponds to a specific sense of a specific word of the language in question. A sememe can be elementary, and then it is called a sene; otherwise, it is complex and is representable in terms of other sememes and/or semes.

Sememes fall into two major classes:

1. functors, or sememes having "places" for other sememes, which are then their arguments, and

2. names (of (classes of) objects), which may only serve as arguments but may not have their own arguments.

The relationship between a functor and its i-th argument is shown, in the semantic language, by an arrow labeled $i$ and pointing from the functor to the argument. For example, 'sleep' is a one-place functor, and therefore, Mary sleeps = 'Mary' 'sleep'; 'need' is a two-place functor, so that
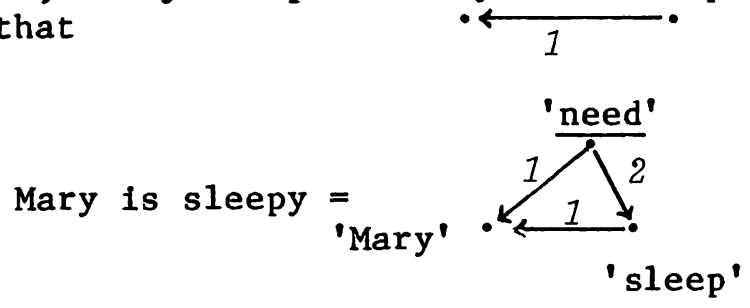

Functors are meanings corresponding to actions (such as 'unite', 'kiss'), states ('sleep', 'disappear', 'joy'), properties ('lovely', 'blue'), relations ('more than', 'be part of'), parameters ('the speed of', 'the price of'), events ('rain', 'explosion', 'fall'), quantities ('many', 'three thousand'), etc. Names are meanings corresponding to objects, substances, natural species, etc.

Functors are subdivided, first according to the number of the arguments they can take (one-place, two-place, etc.; in actual fact, natural languages do not show functors with more than 6 arguments); and second, according to the restrictions on the semantic type of the arguments they can take (both arguments of 'cut' must be names; the only argument of 'begin' must be a functor; the first argument of 'see' must be a name, but the second may be either a name or a functor). There are three major types of functors: predicates, quantifiers and logical connectors, but we will not delve into this matter.

Formation rules for SemR's are trivial and largely obvious. The following are some of the more basic ones:

- a SemR must be a connected, oriented, labeled graph 
- the number of arrows leaving a node which is labeled with a functor must correspond to the number of places of this functor

- no arrow should leave a node labeled with a name

- all the restrictions inherent in functors which appear in a Sem $R$ should be observed

Transformation rules for SemR's are equations which correlate (non-elementary) sememes with their decompositions: 'die 2 ' = 'cease to exist $1^{\prime}=$ 'begin 1 to not exist 1 ', etc. Note that, strictly speaking, we should use semantic networks and write as follows:

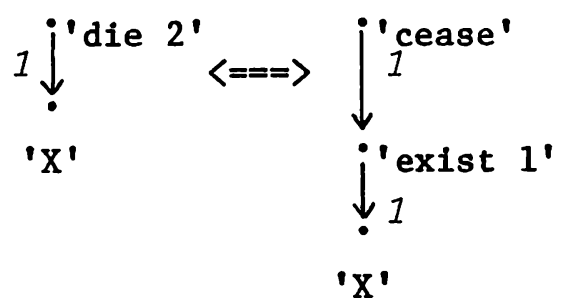

However, here as everywhere below, we allow ourselves to simplify the presentation, if this does not entail ambiguities or misunderstandings.

By means of such rules we can carry out equivalent transformations of SemR's :

'His desire 1 died $2^{\prime}=$ 'His desire 1 ceased to exist $1^{\prime}=$ 'His desire 1 began 1 to not-exist $1^{\prime}$.

Let it be emphasized that a rule of the form ' $X$ dies $2^{\prime}=$ ' $X$ ceases to exist $1^{\prime}$ is nothing more than a lexicographic definition of a particular lexical sense of an English word. It is here that the concept of a special dictionary enters the scene; we will return to it short1y.

Put into a nutshell, the semantic language for, say, English, is a hybrid using the grammar of oriented labeled networks and the English vocabulary, but in a disambiguated form. We take as basic lexical units of the semantic language not words, but word senses defined in terms of more elementary senses, which in their turn are defined in terms of still more elementary senses, and so on, until we arrive at semantic primitives; these latter have to be specified by a list. To achieve this, our definitions should obey precise and rigorous rules (for instance, vicious circles must be banned), which we cannot discuss here. (A few words, though, will be said about them in Sect. 2.) Instead, let us consider a sample SemR: the SemR for a sentence taken from the same issue of The Globe and Mall as mentioned above (Aug. 5, 1985; page N6): 
(16)

Four Soviet soldiers lost on maneuvers in Czechoslovakia traded their tank to a tavern owner for two cases of vodka and were found sleeping off the liquor in a forest two days later, a West German newspaper has reported.

We have to simplify our SemR drastically in order to make it surveyable. Thus, we do not even try to decompose many sememes which are readily decomposable. For instance, we used in the SemR, without further ado, the expressions get lost $[=$ ' come to not know where is the way which one should follow'], sleep off the liquor, maneuvers, exchange, and others. The case of exchange would be especially interesting. Decomposing $X$ exchanges $Y$ with $Z$ for $W$ into ' $X$ causes that $Z$ owns $Y$, which previously $X$ owned, having the goal of thereby causing - and $X$ thereby causes -- that $Z$ causes that $X$ owns $W$, which previously $Y$ owned' would much better show the semantic link between soldiers, vodka and their sleeping off the liquor. Furthermore, sensedistinguishing numbers are not shown with the sememes. We cannot explain, elther, many important details of SemR (17); we will, however, comment on four technical points.

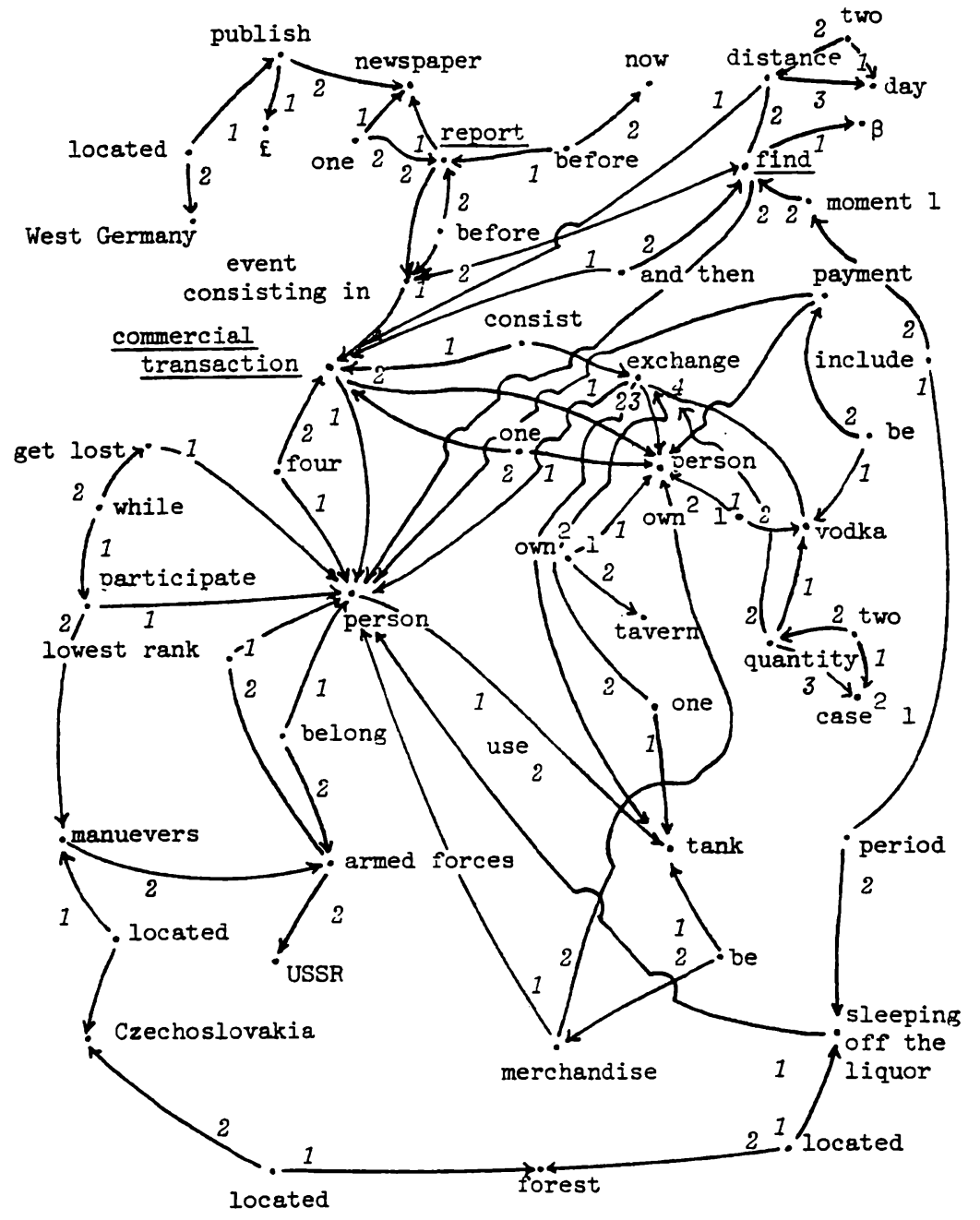


(i) All temporal relations, grammatical or otherwise, are represented in the same homogeneous way: by means of the sememe 'before'. Thus '(to) report before now' renders. (very roughly!) the present perfect of 'has reported'; $X$ two days later than $Y$ appears as ' $Y$ before $X$ (and) the distance between $X$ and $Y$ is two days'; for $X$ were found sleeping... we have 'someone found $X$, the moment of finding being included into the period of X's sleeping'. Similarly, all locative relations are shown in a standard way as well: the sememe '(to be) located in'.

(ii) The sememe 'use' in 'soldiers use tank' is applied very much like the expressions 'use the bathroom' 〈the telephone〉, i.e. in the sense 'to use $X$ the way $X$ is designed to be used'; this is the meaning of the lexical function Real (see below).

(iii) To show the scope of the newspaper's report, a node labeled 'event consisting in ...' is used: the arrows leaving this node identify the two events ('(performed) a commercial transaction' and '(somebody) found...') that enter into this scope.

(iv) The sememes underlying semantic assertions (as opposed to presuppositions and modifications) are underscored, cf. above.

Strictly speaking, the network which appears in (17) is not a SemR; it is only a part of a SemR, namely the so-called Sem(antic) S(tructure) of sentence (16). A complete SemR must include two other parts: the Comm(unicative) S(tructure), which specifies the division of the given meaning into theme (topic) and rheme (comment), given vs. new information, and the like. But as indicated above, for simplicity's sake we suppress the Comms and the Rhet(orical) $\mathrm{S}$ (tructure), which specifies the "artistic intentions of the speaker, and, by obvious metonymy, allow ourselves to call (17) a SemR.

Notice that for pedagogical reasons, it might be more advisable to choose a simpler SemR (i.e. to present a shorter and more trivial sentence), as is often done to illustrate a point. We have, however, preferred not to amuse our readers with toys but rather to show them the real thing, even at the risk of frightening some of them away. The crucial feature of the MTT is that it does face the enormous complexity of natural language semantics, and we feel it is important for our readers to be fully aware of the extent of this complexity.

The Sem $R$ as proposed has a property which is central to the present paper: the elements of a SemR are, generally speaking, "smaller" (i.e. semantically simpler), than the lexemes which must be used in the corresponding sentence. Thus, 'person belonging to the armed forces of $X$ and having the lowest rank therein' is 'soldier'; ' $X$ (performs) a commercial transaction with $Y$ consisting in exchanging by $X$ with $Y$ a $Z$ as a merchandise for $a \mathrm{~W}$ as a payment' is ' $\mathrm{X}$ trades $\mathrm{Z}$ to $\mathrm{Y}$ for $\mathrm{W}$ '; etc. In the Synt(actic) R(epresentation), however, the elements are of course actual lexemes. Therefore, the main bulk of semantic rules of a 
language, that is, of the rules that correlate the SemR and the SyntR conveying the same meaning, is composed of rules having the following form:

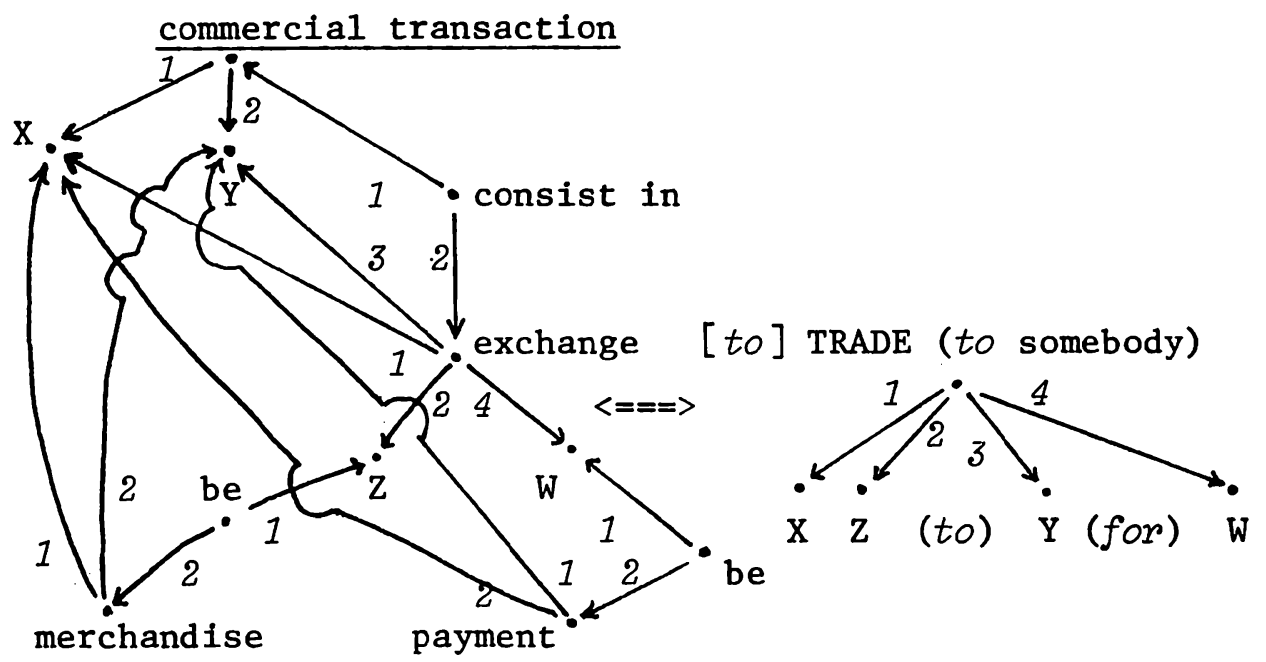

There are other types of semantic rules as well; e.g., rules that map sememes onto morphological categories, such as tenses ('before now' $\langle=\Rightarrow$ past tense), grammatical numbers, etc., which appear in syntactic structures. But semantic rules of type (18) are by far the most numerous: for a given language, they number between $10^{5}$ and $10^{7}--$ since every such rule represents a particular lexeme, or a word sense.

Now, a semantic rule of type (18) is nothing else but (with all additional data concerning cooccurrence) a DICTIONARY (= LEXICAL) ENTRY. From this it follows that semantics is, roughly speaking, a dictionary, but a very specific dictionary. We will characterize it in Sect. 3.

3 The Explanatory Combinatorial Dictionary as a Crucial Component of a Meaning-Text Model

\subsection{General Characteristics}

The Explanatory Combinatorial Dictionary (ECD) differs from more familiar monolingual dictionaries in that it is not a commercial dictionary which aims at a particular public, is adapted to fulfill a particular task, and is bound to observe various pedagogical, typographical and financial constraints. An ECD is conceived and developed as one part of a scientific (theoretical) description of the language under analysis and is thus a theoretical lexicon (cf. Lakoff 1973: 162-164). An ECD is to a "normal" dictionary what a theoretical grammar is to a language textbook. This fundamental property entails the following five features typical of an ECD: 
1. An ECD is a production-oriented dictionary: it is intended to supply all the information which is conveyed by lexical units and which is necessary to express a given thought, and is oriented in conformity with the orientation of the meaning-text model.

2. An ECD is a semantics-based dictionary (that is why it is called explanatory). The definition of the entry lexeme, written in the special semantic language discussed above, serves as a basis for the description of the paradigmatic and syntagmatic relations of this lexeme.

3. An ECD is a combinatorial dictionary: it describes the syntactic and lexical collocations of the entry lexeme in the greatest possible detail.

4. An ECD is a systematic dictionary: it lays heavy emphas is on the homogeneity of the lexicographic descriptions. It is developed by lexical fields rather than by alphabet: similar lexemes have similar descriptions; all links existing between the definitions and the syntactic cooccurrence of a lexeme must be made explicit; etc.

5. An ECD is a formal dictionary: all information is presented by means of a rich lexicographic metalanguage, which ensures a rigor never before attempted in lexicography.

Consistent with these five properties, an ECD features a standard, rigid structure for its entries, as described below.

\subsection{Structure of an ECD Entry}

Our discussion of ECD entries will draw. on examples from the recently published Russian ECD (Mel'Cuk and Zholkovsky 1984); the interested reader can also consult the first volume of the French ECD (Mel'ruk et al. 1984).

The basic unit of an explanatory combinatorial dictionary is a dictionary entry corresponding to a single lexeme or a single phrasene -- one word or one phraseme taken in one separate sense. A family of dictionary entries for lexemes which are sufficiently close in meaning and which share the same signans (identical stem) is subsumed under one vocable, which is identified in upper-case letters.

Different vocables which are the same graphically (homonyms) are distinguished by numerical superscripts: Russ. BRAK ${ }^{1}$ 'marriage' vs. $\mathrm{BRAK}^{2}$ 'defective merchandise'.

The lexemes within a single vocable are distinguished by special indices mentioned here in order of increasing semantic proximity (cf. the use of numerical distinguishers for sememes, illustrated above): 
Roman numerals differentiate lexemes whose definitions have a non-trivial common semantic component but whose semantic relationships are not sufficiently regular:

VYSOTA I 'height or altitude [as a vertical measure]' VYSOTA II 'level [of prices, aspirations, pressure]' VYSOTA III 'pitch [of sound]' VYSOTA IV 'altitude [of the sun over the horizon]' VYSOTA $V$ 'altitude [of a triangle]'.

Arabic numerals indicate sufficiently regular semantic relationships among lexemes that share non-trivial semantic components, or regular polysemy: e.g. SPAT' ${ }^{1}$ I.1 'sleep' vs. SPAT'l I.2 'be inert, as if sleeping'. The literal and the figurative meanings of vspyxivat' 'blaze up/flare up' are distinguished in this way, as are kipet' 'bo11/seethe with', zastyt' 'congeal/become st111 [with fright, etc.]'; and the like.

Lower-case letters differentiate lexemes with slight semantic differences which are maximally regular: e.g. SKOROST' la 'speed' and SKOROST' 1b 'great speed'. The same goes for vysota 'height', temperatura 'temperature/high temperature', kaXestvo 'quality/excellent quality', etc.

It should be stressed that all full idioms are entered in the ECD separately. (A full Idiom is a phrase whose meaning cannot be computed from the meanings of its words and such that no constituent word retains its full meaning; cf. shoot the breeze or More power to hin: in English.) Full idioms are provided with dictionary entries as if they were single lexemes; for example, 12 ljubvi k lskusstvu 'for the love of the thing' or kolot' glaza 'to throw something in somebody's teeth'. Thus the ECD does not distinguish between mono-lexemic and multi-lexemic units as head entities in its entries.

An ECD entry is divided into three major zones (we will not even mention other subdivisions, which are less important in the present context, such as morphological information, usage labels, etc.):

- semantic zone

-syntactic zone

-lexical cooccurrence zone

3.2.1 Senantic Zone. The semantic zone contains the SemR of the entry lexeme, or its definition, written in accordance with the following six principles :

(1) Generally speaking, the definiendum is not simply an entry lexeme but rather a propositional form: the lexeme with variables representing its semantic actants, or argument roles. Thus we define not 'to help' but rather ' $X$ helps $Y$ in $Z$ by/with $W$ '; not 'aggression' but 
'aggression of $\mathrm{X}$ against $\mathrm{Y}$ '; not 'faithful' but ' faithful to $\mathrm{Y}^{\prime}$; etc.

(11) The definiens is formulated in terms of lexemes which are semantically simpler than the entry lexeme (= definiendum). ' $X$ is semantically simpler than $Y$ ' means that we need $X$ to define $Y$ but $Y$ cannot (and will not) be used to define $X$. Thus if 'maneuvers of $X$ ' is defined as 'a large-scale training exercise of the armed forces $X$ simulating combat', then 'maneuvers' cannot appear in the definitions of 'large-scale', 'train', 'exercise', 'armed forces', etc. This entails the senantic decomposition of any entry word, which in its turn, precludes vicious circles -- that common plague of practically all existing dictionaries. Consistently applied, semantic decompositions lead to a set of semantic primitives.

(111) In the definiens, neither ambiguity nor synonymy of terms are allowed. To avoid ambiguity, the definition is written in terms of word senses, 1.e. lexemes (lexical units supplied with distinctive indices, as specified above) rather than in terms of polysemous words. To avoid synonymy, just one expression is chosen and fixed explicitly for any meaning; e.g., we say only 'having the goal of' instead of '(in order) to', 'aiming at' or 'with the aim/goal of' etc. (In this way, an ECD ensures univocality of defining terms.)

(iv) The definiendum and the definiens are strictly synonymous, and ABSOLUTE MUTUAL SUBSTITUTABILITY is required of them in all possible contexts. This means that a definition in an ECD contains only necessary components such that, taken together, they are sufficient to uniquely specify the definiendum. (This is the adequacy principle.)

(v) Any lexemes that belong to the same vocable, i.e. that are semantically related, must show this relatedness explicitly -- by displaying an identical semantic component, called semantic bridge.

(vi) Any vocables that are semantically related must be organized according to the same pattern: they show roughly the same number and order of related lexemes, the definitions of lexemes are written following the same general schema, etc. (This is the uniformity principle; it is directly linked to the systematic character of an ECD and its field structure.) 
As an example, let us quote the definition of Russ. SKOROST' la 'speed':

$$
\begin{aligned}
& \text { SKOROST' } P-a / X-a-Y ' \text { the speed of } P / X \text { being } \\
& Y^{\prime}=\text { 'quantity II which characterizes } 2 \text { the motion } \\
& I .1 P \text { of } X \text { by the distance I. } 2 a \mathrm{Y} \text { which } X \text { covers } \\
& \text { III in unit } 4 \text { time } 2 \text {, or the value } 6 \text { of this } \\
& \text { quantity II'. }
\end{aligned}
$$

3.2.2 Syntactic Zone. An ECD fully specifies all the expressions which can be syntactically headed by the entry lexeme and which are "bound" by it (which are not free but rather idiomatic,) to a lesser or greater extent, with respect to the given entry. This is done by means of the so-called government pattern (GP). A GP is a table in which each column represents one semantic actant of the lexeme (marked by the

\begin{tabular}{|c|c|}
\hline $1=P$ or $1=X$ & $2=Y$ \\
\hline $\begin{array}{l}\text { 1. } \mathrm{N}_{\text {gen }} \\
\text { 2. A } A_{\text {poss }}\end{array}$ & 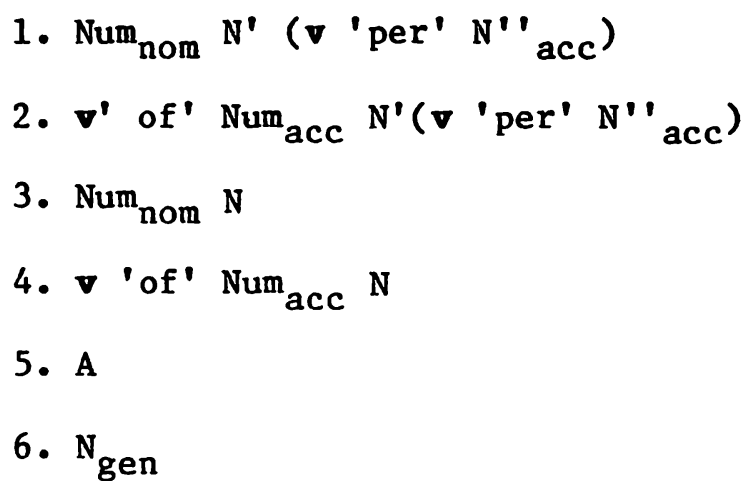 \\
\hline
\end{tabular}
corresponding variable), and each element in the column represents one of the possible surface realizations of the corresponding syntactic actant. For instance, the GP for the Russian lexeme skorost' $1 \mathrm{a}$ 'speed' has the form:

This GP specifies that the first deep-syntactic actant of the lexeme skorost' la 'speed' fills the slot of the variable $P$ or $X$ in its definition ( $1=P$ or $1=X$, where $X$ stands for the body, and $P$ stands for the motion of the body whose speed is described). The second deep-syntactic actant fills the slot of the variable $\mathrm{Y}(2=\mathrm{Y}, \mathrm{Y}$ being the value of the speed). The first deep-syntactic actant may be expressed on the surface either as a noun in the genitive case or as a possessive adjective (skorost' samoleta 'the speed of a plane', nasa skorost' 'our speed'). The second deep-syntactic actant has six surface realizations :

1) a complex noun phrase in the nominative consisting of two phrases: a noun phrase "Numeral in the nominative + Noun denoting unit distance" and a prepositional phrase "v 'per' + Noun denoting unit time", for 
instance, skorost' desjat' kilometrov ( $v$ Cas) 'a speed of ten kilometers (per hour)'.

For the other five realizations we shall restrict ourselves to examples:

2) skorost' $\nabla$ desjat' kilometrov ( $v$ Cas) 'a speed of ten kilometers (per hour)',

3) skorost' 40 uzlov 'a speed of 40 knots',

4) skorost' $\nabla 40$ uzlov 'a speed of 40 knots',

5) kosmiCeskaja 〈tysjakekflometrovaja〉 skorost' 'cosmic 〈1000-kilometer> speed', and

6) skorost' sveta 〈zvuka〉 'speed of light 〈of sound〉'.

A GP is usually provided with a number of restrictions. These are rules which establish the conditions under which the deep- or surface-syntactic actants of the entry lexeme can cooccur, and give all possible details relevant to the combinability of the lexeme in question with its syntactic actants.

The notations used are:

$M_{1,2,3 \ldots}$ - 1st, 2nd, 3rd, ... deep-syntactic actant of the lexeme

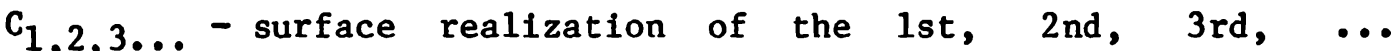
deep-syntactic actant (in most cases, this realization is the grammatical subject or the 1 st, 2 nd, ... complement of the lexeme but it may also be an attribute or adverbial modifier)

$\mathrm{C}_{1 . j}-\mathrm{a}$ specific means of marking the surface-syntactic element $C_{1}$ (that is, 1 is the number of the column in the GP, and $j$ is the number of the element in that column)

For Instance, the GP of the lexeme skorost' la has such restrictions as:

2) $C_{2.1,2.2:} \mathrm{N}^{\prime}$ is unit distance [metr 'meter' fut 'foot', ....], $N^{\prime \prime}$ is unit time [sekunda 'second', mesjac 'month', ....]

3) $C_{2.3,2.4}: \mathrm{N}$ is a unit speed [uzel 'knot', $\max$ 'Mach', ...]

6) Impossible: $C_{1}+C_{2.6}$

7) Undesirable: $C_{1}+C_{2.1-2.4}$, if $M_{1}$ is not a movement and skorost" does not depend on pri 'under'.

The GP and all the restrictions on it are exemplified by all possible combinations of the entry lexeme with its actants as well as by all the impossible combinations prohibited by those restrictions. Every 
starred example is followed by the number of the restriction it violates.

3.2.3 Lexical Cooccurrence Zone. This zone embodies the major novelty proposed in an ECD: namely, exhaustive and systematic description of restricted lexical cooccurrence of the entry lexeme. We mean the type of lexical collocation boldfaced in (20) -- a dozen sentences collected in ten minutes from one newspaper page:

a. The President clamped (imposed) an overnight curfew on three areas ... to stamp out (put down) violence.

b. The panel issued a report to the Secretary of State.

c. President Reagan rejected pleas to open talks with striking US controllers.

d. Pope released from hospital [headline]. The Pope left the hospital yesterday, three months and one day after he was struck by two bullets. He said a brief prayer ...

e. The heaviest prison terms in Kentucky history (more than 1,600 years each) have been handed down against two men.

f. South African troops have spread a dragnet across the country in search for three heavily armed black guerillas.

g. The ANC has claimed responsibility for the attack launched last Tuesday in which four rockets were fired at an army camp.

h. We are looking for senior consultants of proven competence to satisfy the dewands of our growing business.

Texts, from colloquial to artistic to technical, swarm with expressions of this type.

To describe all such collocations, the important concept of lexical function (LF) has been introduced.

A lexical function $f$ is, like any mathematical function, a dependency that associates with a given "independent quantity" (the argument), a "dependent quantity" (the value). More precisely, an LF $f$ associates with a lexical unit $W$ (a word or a phrase) a set $\left\{W_{1}\right\}$ of (more or less synonymous) lexical units that express, contingent on $\omega, a$ specific idea (such as 'very', 'begin', 'implement') represented by $f$. For example, the LF Magn (for the present glossed roughly as 'very') in 
conjunction with the Russian words naprjazenie 'voltage' or temperatura 'temperature' is expressed by the adjective vysokij 'high'. In conjunction with vysota 'height', however, the same function is expressed by znaxitel'nyj 'considerable', bol'zoj 'great' or ogromnj 'enormous'; and in conjunction with vibracija 'vibration', by sil'nyj 'strong' or intensivnyj 'Intense'. Thus we get vysokoe naprjazenie 'high voltage', vysokaja temperatura 'high temperature', znakitel'naja (bol'zaja, ogromaja) vysota 'considerable (great, enormous) helght', and sil'naja (intensivnaja) vibracija 'strong (intense) vibration'; but we do not get *sil'noe (znakitel'noe) naprjazenie, *bol'zaja (Intensivnaja, sil'naja) teaperatura, *intensivnaja (sil'naja) vysota, *ysokaja (bol'zaja) vibracija, etc.

The importance of LFs consists in the discovery of the following fact: in all natural languages there is only a limited number of meanings (about several dozen) that resemble 'very' in that they also each determine an LF.

And now, a formal definition of lexical function:

A dependency $f$ is called lexical function if and only if it associates with a lexical unit $W$ (a lexeme or a phraseme, the argument of $f$ ), a set $f(W)=\left\{W_{f}\right\}$ of lexical units (the value of $f$ ), such that the following two conditions are simultaneously met:

For any two different $w^{1}$ and $w^{2}$, if $f\left(w^{1}\right)$ and $f\left(w^{2}\right)$ both exist, then:

1. Both $\mathbf{f}\left(\boldsymbol{w}^{1}\right)$ and $\mathbf{f}\left(\boldsymbol{w}^{2}\right)$ bear an identical relationship with respect to meaning and deep-syntactic role to $\mathbf{w}^{1}$ and $\mathbf{w}^{2}$, respectively. [This condition is language-independent.]

2. In some cases, at least, $f\left(w^{1}\right) \neq f\left(w^{2}\right)$. [This condition is completely language-dependent; it means that in the given language, the value of $f$ is phraseologically bound by its argument.]

An important proviso: A lexical function is not a genuine semantic unit, let alone a semantic primitive. LF's are introduced to describe restricted lexical cooccurrence and derivation, but by no means semantics. First, there are LF's that are semantically empty, their values being limited to purely syntactic roles (cf. Oper , $_{i}$ Punc $_{i}$, Labor $_{i j}$ below). Second, the expressions making up the value of a given LF f for a given argument need not be perfectly synonymous; it suffices for them to share a rather general and abstract meaning ' $f$ ' while differing in other components.

We will be interested in a particular type of LF, namely standard lexical functions, which form a proper subset of all lexical functions. A standard LF simultaneously satisfies two additional conditions: 
3. The LF $f$ is defined for a sufficiently large number of arguments. In other words, $f$ has a sufficiently large semantic cooccurrence: its meaning ' $f$ ' is sufficlently abstract to be compatible with a large number of other meanings. [This condition is language-independent.]

4. The LF $f$ has a sufficiently large number of linguistic expressions as its possible values. In other words, the set of all $f\left(w_{i}\right)$, for a vast variety of $w_{i}$, is sufficiently rich. [This condition is completely language-dependent.]

Let us illustrate this point with two examples. The meaning 'manufactured from very dark rye flour' in Russian has three expressions: Eernyj 'black', rzanoj 'rye [Adj]' and $\mathbf{1 z}$ rzanoj muki 'from rye flour', and these expressions are phraseologically bound: Only xleb 'bread' or suxar' 'rusk' can be called Eernyj, while very dark rye bulocka 'bun', bublik 'bagel', blin 'pancake', korz(ik) '(a kind of) flat, dense, dry bread', le perzka 'a flat cake', etc. cannot; *rernaja bulozka 'black bun' is readily understandable but ungrammatical.

Only xleb 'bread' and lepezka 'flat cake' but nothing else can be called rzanoj. (Notice that Cèrnyj xleb is always rzanoj xleb, but rzanoj xleb can be svetlyj 'light', as well as Eernyj.)

(Speaking of bulorki, bubliki, bliny, korzi and korziki, Russian uses iz ryanoj muki (but not with reference to suxari 'rusks' and hardly with reference to xleb): ‡kernyj/rzanoj bublik, etc.)

As we see, this meaning satisfies Conditions 1 and 2 (Eernyj: xleb $=12$ rŽanoj muk1: bublik = rZanaja: lepełka vs. *rŽanaja buloßka, ...) and therefore specifies a lexical function. However, this meaning violates Conditions 3 and 4 : it is conceivable only with the names of bread-like baked products made from dough (so that it is semantically too specific) and it has only three expressions. Therefore, it is not a standard LF.

The meaning 'it is necessary to $P$ this $X$ ' has in Russian a phraseologically bound expression nutdat'sja 'need' that is possible with some P's while impossible with others: Bta stat'ja nuzdaetsja v ispravlenil < $v$ dorabotke> 'This paper needs to be corrected 〈more work>' but not *ìta stat'ja nuzdaets ja $v$ soxraneli 〈v otpravke avtoru〉 'This paper needs to be saved <to be sent to the author>'. This meaning satisfies, in addition to Conditions 1 and 2 , Condition 3 (it is extremely abstract), but it still violates Condition 4. (There are not numerous synonymous expressions. In fact, there is only one other expression for the meaning in question satisfying Condition 1: trebovat' 'require', which is in free variation with nuzdat'sja).

Both above-mentioned meanings, 'manufactured from very dark rye flour' and 'it is necessary to $P$ this $X$ ', are non-standard LF's in Russian. In what follows, only standard LF's are considered. 
Since both defining conditions for standard LF's include the vague expression 'sufficiently large number', there is no sharp borderline between standard and non-standard LF's. That is, there are no formal criteria to tell them apart. This fact reflects the graduality so typical of natural languages. The concept of standard LF is fuzzy, as are most linguistic concepts.

Within the class of standard lexical functions, we will distinguish simple LF's and compound LF's, the latter being built out of the former. Notice that simple in this context by no means implies 'elementary' or 'further unanalyzable': some of our simple LF's could be represented in terms of other simple LF's (and thus could be treated as compound). Nevertheless, for purely linguistic reasons (primarily, frequency of occurrence) we consider a particular set of LF's as simple and take this set to be the basis of lexicographic descriptions.

The list of lexical functions which comprises the main body of our systematic survey is found in Appendix A. It includes only simple standard LF's. (This allows us to omit the adjectives "simple standard" everywhere, since the omission cannot lead to a confusion.)

Along with the LF's listed in Appendix A, two further types of LF's are extensively used in the Explanatory Combinatorial Dictionary: non-standard and compound LF's.

A non-standard $L F$ is a meaning that is idiomatically expressed depending on a key word, but that has either a strongly limited semantic combinability or a fairly limited range of expressions, or both. In other words, it is too specific, too particular to be granted the status of a standard LF. Non-standard LF's are written in standardized natural language. Some examples:

$$
\text { such that } \mathrm{Y} \text { is confined to his home (arest 'arrest') = }
$$
domašnij 'house-[arest]'

such that it is the result of a loss at cards that was not immediately pald (dolg 'debt') = kartoknyj 'card' [dolg], obsolete: [dolg] zesti '[debt] of honor'

during a short time and/or nonintensively (with the purpose of knowing $Y$ somewhat better) (urit'sja 'learn') = // poducit's ja 'learn a bit (of something)'

A compound LF is a combination of syntactically related simple LF's that has a unique lexical expression covering the meaning of the combination as a whole. I have presented numerous examples of compound LF's in Appendix A; let me give some more illustrations, with the key word printed in boldface: 
Antikagn

Antiver

Causoper $_{2}$

AntiReal 2

IncepOper $_{1}$
: Zidkie aplodismenty 'thin (1it. 'liquid') applause' slabye dovody 'weak arguments' nizkaja temperatura 'low temperature' neznałitel'nye poter1 'negligible losses'

: ložnyj styd 'false shame' Izivoe obešanie 'false (11t. 'Iying') promise' osibornoe predstavlente 'a wrong conception' bezosnovatel'nye opasenija 'unfounded misgivings/ fears ${ }^{\prime}$

: priobretat' populjarnost' 'acquire popularity' vpadat' $v$ otלajanie 'sink into despair' vstavat' na put' predatel'stva 'take the path of treason' perexodit' $v$ pike 'go into a dive [as of an aircraft]'

: sdavat' v èkspluataciju 'put into operation' vvergat $v$ rabstvo 'plunge into slavery' stavit' pod kontro1 'put under control'

: provalit'sja na èkzamene 'fail an examination' otvergat' sovet 'reject a piece of advice' otklonjat' xodatajstvo 'turn down an application'

The following four remarks bearing on all LF's are in order:

(i) An LF may have a fused expression, i.e. a lexical unit that does not include the key word but covers both the meaning of the function itself and that of its argument (the key word). The fusion is shown by the symbol // separating all the fused values (on its right) from all the non-fused values. For example:

Magn(dozd' 'rain') = prolivnoj 'heavy' // liven' 'shower' [i.e., liven' = prolivnoj dozd'; cf. Engl. downpour = heavy rain].

Magn(vkusno 'delicious') = oren' 'very' // pal'とiki obližes', 1it. 'You'11 lick your fingers' [pal'ziki obliž' $=$ ocen' vkusno]

(ii) Several LF's which simultaneously have the same key word but are syntactically not linked to one another may be expressed by one lexical unit covering the meanings of all the LF's involved. This is what we call configuration of LF's (as opposed to compound LF's, in which all the constituent-simple LF's are syntactically linked). In a configuration of LF's, the " + " sign is used to separate the constituents. For example, in the entry SUD'BA 1 'fate, destiny' the notation

$$
\text { Fact }_{3} \text { II }+ \text { AntiBon }_{2}: \text { presledovat' 'persecute' }
$$


means that fate really affects $\left[=\right.$ Fact $\left._{3}{ }^{I I}\right]$ the person in question (the defendant, so to speak) and its verdict is bad [ $=$ AntiBon $_{2}$ ]. Two further examples:

$A_{1}$ (vosxišrenie 'delight') + Magn(vosxišenie) $=$ preispolnennyj [vosxiscenija] 'full [of delight]'

Oper $_{1}$ (otČajanie 'despair') +

Magn(otð̌ajanie) = byt' vo vlasti [otX̌ajanija] 'be completely in [despair]'.

(iii) Some LF's (most often, Magn or Real ${ }_{1}$ with the latter's relatives, Fact $_{1}$ and Labreal $_{1 j}$ ) may be subscripted with a semantic component of the key-word's definition (in square brackets) to indicate that the meaning of this LF interacts with exactly this component of the key-word's meaning. Thus:

Labreal $_{12 \text { [xranit' 'keep'] (pamjat' }}$ 'computer memory') $=$ xranit' [v pamjat1] 'store [in memory]'

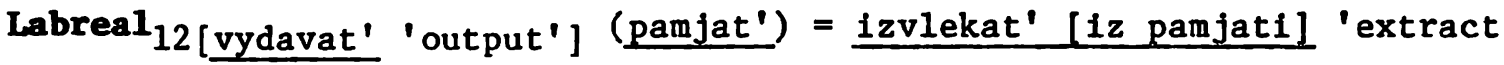
[from the memory]'

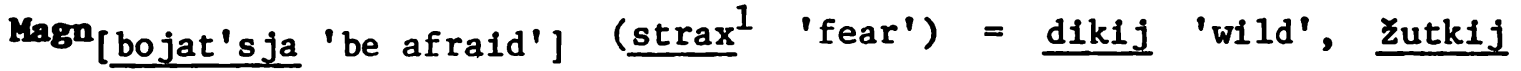
'terrible'

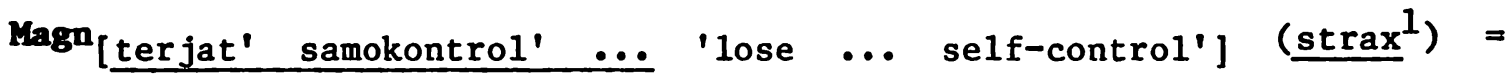
panireskij 'panic [adj•]', Ziivotnyj 'animal'

AntiVer [poražat' 'hit'] (streljat'l 'shoot') = ploxo 'badly, skverno 'poorly'

AntiVer [cel' 'target'] $\left(\right.$ streljat $\left.^{1}\right)=\underline{v}$ vozdux 'into the air'

(iv) Furthermore, some LF's may be superscripted with semantic labels, like 'usual', 'loc(ation)', 'temp(oral)', 'quant(itative)', to make their meaning more precise:

Magn $^{\text {temp }}$ (opyt 'experience') $=$ dlitel'nyj 'long'

Magnquant (opyt 'experience') = bol'క̧oj 'considerable' 
In concluding this survey of LF's we would like once again to call attention to the fact that they are used for two main purposes:

1) for the description of idiomatic or restricted lexical cooccurrence or derivational relations; and

2) for specifying universal synonymic transformations of utterances on the deep-syntactic level.

It is clear, for example, that in any language (24) holds:

$$
\begin{aligned}
& w=\operatorname{oper}_{1}-2->s_{0}(w)=\operatorname{oper}_{2}-2->s_{0}(w) \\
& =\text { Punc }_{1}{ }^{1->S_{0}}(W)=\text { Punc }_{2}{ }^{1->S_{0}}(W)=\text { Labor }_{12^{-2}}->S_{0}(W) \text {; and so on. }
\end{aligned}
$$

[Numbers on the arrows stand for deep-syntactic actants; e.g., the key word of an Oper is its second deep actant, etc.]

follows :

The transformations presented in (24) can be exemplified as

$$
\begin{aligned}
& \text { 'vlijat' } '(\text { to }) \text { influence' }=\text { okazyvat' }\left[=\text { oper }_{1}\right] \text { vlijanie }\left[=\mathbf{s}_{0}\right] \\
& \text { influence' = byt', naxodit'sja [= } \left.\text { Oper }_{2}\right] \text { pod vlijaniem 'be under } \\
& \text { influence', etc. }
\end{aligned}
$$

Compare (26):

(26) Ivan durno vlijaet na Petra

'John Influences Peter badly' =

Ivan okazyvaet na Petra durnoe vlijanie

'John has a bad Influence on Peter' =

Pëtr naxoditsja pod durnym vlijaniem Ivana

'Peter is under the bad influence of John'.

Rules of type (24) allow one to develop a paraphrasing system for synonymic transformations of sentences and/or discourses. Such a system can automatically produce, for any given text, a set of its synonymous or nearly-synonymous paraphrases. It also can automatically derive, for a set of synonymous texts, a canonical invariant. 
Appendix A: List of Lexical Punctions

A lexical function, notated by a boldfaced Latin abbreviation, is written before the parentheses enclosing its argument (a familiar mathematical functional notation). For example:

Function Argumen
Magn(shave)
Magn(easy)
Magn( scoundre1)
Magn( condemn)
Magn(cold)

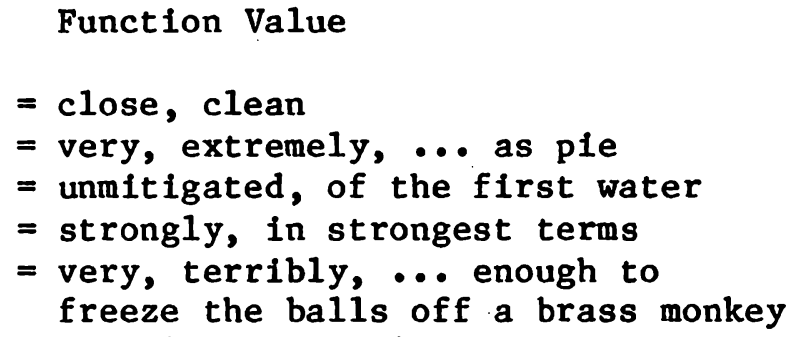

As stated in Section 3.2.3, LF's are one of the central notions to a new type of dictionary, the Explanatory Combinatorial Dictionary. The simple standard lexical functions will be listed below in the order in which they appear in a lexical entry in such a dictionary.

1. Syn - synonym; Syn ${ }_{\supset} S_{\mathbf{S n}_{C}}$ and $\mathbf{S y n}_{n}$ designate, respectively, synonyms with broader, with narrower, and with intersecting meanings. (Symbols $\supset, c$, and $n$ have the same meaning when used with Conv, Anti and other LF'so) Examples: $\operatorname{Syn}($ streljat' 'shoot') = palit' 'fire'; Syn (streljat' 'shoot') = obstrelivat' 'fire upon, shell, machine-gun'; etc.

2. $\mathrm{Conv}_{1 j}$ - conversive, 1.e., a lexical item with the same meaning as the key word $\boldsymbol{W}$ but with deep syntactic actants $i$ and $\mathbf{j}$ permuted: $\operatorname{Conv}_{21}$ (vključat' 'include') = prinadležat' 'belong to [a set]'; Conv 231 (mnenie 'opinion') = reputacija 'reputation' . ['Reputation', in contrast to 'opinion', is necessarily held by several people; this is why it is a narrower conversive.]

3. Ant1 - antonym: Anti(pobeda 'victory') = poraženie 'defeat'.

4. Gener - Generic concept such that 'Gener $+W$ ' $=$ ' $W$ ' (where $W$ is the key word): Gener(gaz 'gas') = vescestvo 'substance' [cf. gazoobraznoe vešestvo 'gaslike substance' = $\underline{\text { gaz 'gas'] }}$

5. Figur - Standard metaphor for W: Figur(blokada 'blockade) = kol'co, 11t. 'ring' [kol'co blokady 'the grip of a blockade; a siege'];

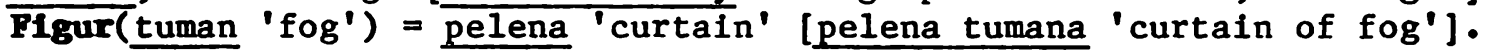

6-9. $S_{0}, A_{0}, A_{d} v_{0}, \nabla_{0}$ - syntactic derivatives of $W ;$ that is: noun (= substantival), adjective, adverb, and verb, respectively, which have the same meaning as $W$. Examples: $S_{0}$ (streljat' 'shoot') = strel'ba 'shooting'; $A_{0}($ streljat' shoot') = strelkovyj 'shooting [attrib.]'; etc. 
10. $S_{1}$ - standard name of the 1-th participant in the situa-

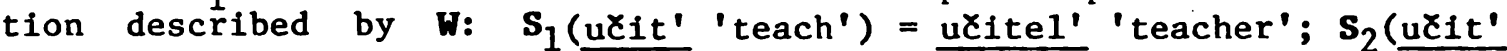
'teach') = uXenik 'pupili'; $\mathbf{s}_{3}$ (uXit' 'teach') $=$ (uXebnyj) predmet '(subject) matter [as in high school]'.

11-15. $\mathbf{s}_{\text {instr }}, \mathbf{s}_{\text {med }}, \mathbf{s}_{\text {mod }}, \mathbf{s}_{10 c}, \mathbf{s}_{\text {res }}-$ standard name of instrument, means, mode, location, and result of the situation described by $\boldsymbol{W : ~} \mathbf{S}_{\text {instr }}$ (streljat' 'shoot') = ognestrel'noe oružie 'firearm';

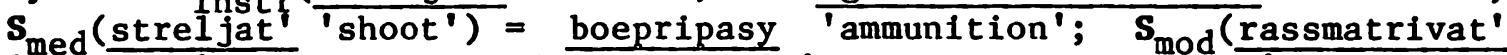
'consider') $=$ vzgljad [na לto-1.] 'a view [of something]'; podxod [k Cemu-1.] 'approach [to something]'; $\mathbf{S}_{10 c}$ (srazat's ja 'fight [as of two armies]') $=$ pole bitvy/boja 'battlefield'; Sres (ưit'sja 'learn') = navyki 'skills', znanija 'knowledge'.

16. Sing - 'one instance/unit of': $\mathbf{S i n g ( g o r o x}$ 'peas') = gorosina 'pea'; Sing(celovat' '[to] kiss') = pocelovat' 'give a kiss'.

17. Hult - 'aggregate of': Mult(korabl' 'ship') = flot 'fleet'; Mult (student 'student') $=$ studenCestvo 'student body'.6

18. Cap - 'head of': Cap(universitet 'university') = rektor 'president'; Cap(fakul'tet 'faculty, school') $=$ dekan 'dean'.

19. Equip - 'staff/crew of'; Bquip(teatr 'theatre') = truppa 'troupe'; Bquip(bol'nica 'hospital') = personal 'personnel; Equip(brak 'marriage') = suprugi 'spouses'.

20. Centr - 'center/culmination of'; Centr(les 'forest') = ‘ašra [lesa] 'the thick [of the forest]'; Centr(slava 'glory') = verรina [slavy] 'summit [of glory]'; Centr(bor'ba 'struggle') = apogej [por'by] 'climax [of struggle]'. Centr is current in combination with Loc in (see $^{-1}$ below): Loc $_{\text {in }}$ Centr(pustynja 'desert') $=\mathrm{v}$ serdce [pustyni] 'in the heart [of the desert]'; Loc ${ }_{\text {in }}$ Centr( doroga road') = posredi [dorogi] 'in the middle [of the road]'.

21. A - determining property of the 1-th participant of a situation characterizing him according to his role in the situation: $A_{1}$ (gnev 'anger') $=v$ [gneve] 'in [anger]', razgnevannyj 'angry';

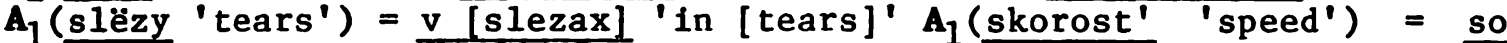
[skorost'ju...] 'with a speed of...' [ compare spusk s takoj skorost'ju the descent with such a speed']; $A_{2}$ (streljat' 'shoot') = pod obstrelom 'under fire'.

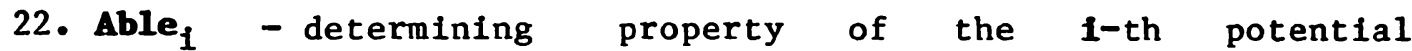
participant of a situation ('such that it can ... easily'/'such that it

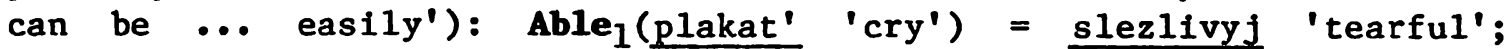
$\mathrm{Able}_{2}$ (somnevat's ja 'doubt') = somnitel'nyj 'doubtfu'́'.

23. Magn - 'very', 'to a (very) high degree': Magn(temperatura 'temperature') = vysokaja 'high'; Magn(rassmatrivat' 'examine') = vnimatel'no 'attentively', pristal'no 'fixedly, intently'. 
24-25. Plus, Minus - respectively, 'more' or 'less' (or 'to a greater/lesser extent') [than something else].

26-27. Plus ref1, Minus ${ }^{\text {refl }}$ - indicate that the comparison is made with a former state of the same object: IncepPredPlus ${ }^{\text {ref }}{ }^{1}$ (temperatura 'temperature') = povysat'sja 'rise, increase' [For the Lf's Incep and Pred, see below.]

28. Ver - 'as it should be' [meeting intended requirements]: Ver(udivlenie 'surprise') $=$ iskrennee 'sincere', nepoddel'noe 'unfeigned'; Ver(sosud 'container') = celyj 'whole', 'hermetical, leak-proof'; Ver(pribor 'instrument') = toenyj 'precise'.

29. Bon - 'good' [a standard praise for $\boldsymbol{W}$ ]: Bon(rezat' 'cut') = akkuratno 'neatly, cleanly'; Bon(sudno' ${ }^{1}$ 'ship) = 'comfortable'.

30. Pos $_{i}$ - a standard praise of one of the participants of the situation denoted by $w$ [but not of the situation itself]: Pos $_{2}$ (recenzija 'review') = položitel'naja 'positive', while Bon(recenzija review') = xorošja 'good, zamexatel'naja 'excellent', ..., blestjašaja 'brilliant'; however, a blestjašcaja recenzija 'a brilliant(1y written) review' may well be položitel'naja 'positive' or otricatel'naja 'negative', that is, Pos $_{2}$ or AntiPos $_{2}$.

[NB: The LF's Magn, Ver, Bon and Pos, are often combined with Anti. Thus, for instance, Magn(temperatura 'temperature') $=$ vysokaja 'high, and AntiMagn(temperatura 'temperature) $=$ nizkaja ' 1 low'; Pos $_{2}$ (mnenie

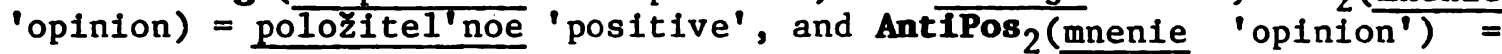
otricatel'noe 'negative'.]

31. $\mathbf{A d v}_{\mathbf{i}}$ - determining property of an action by the $\mathbf{i - t h}$ participant of a situation according to his role in the situation: $\mathbf{A d v}_{1}$ (slëzy 'tears) = so [slezami] 'with [tears]'; $\mathbf{A d v}_{1}$ (skorost' 'speed') = so skorost'ju ... 'at a speed of ...' [cf. mXat's ja so skorost' ju ... 'tear along at a ... speed']; $\mathbf{A d v}_{2}$ (somnevat's ja 'doubt') $=\underline{\operatorname{vr} j a d ~ 1 i}$ 'hardly'.

32-34. Loc $_{\text {in }}$, Loc $a b$, Loc ad - preposition governing $W[=$ the name of the situation] and designating a type of localization in space with the respective meaning -- position, moving away, moving toward. Examples: Loc $_{\text {in (vysota }}$ 'height') $=$ na [vysote] 'at [a height]';

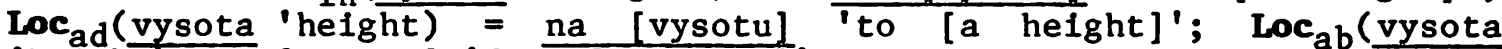
'heliht) $=\underline{s}$ [vysoty] 'from [a height]'.

35. Loc temp - a preposition [analogous to Loc] with the meaning of temporal localization: Loctemp (arest 'arrest') = pri [areste] 'while

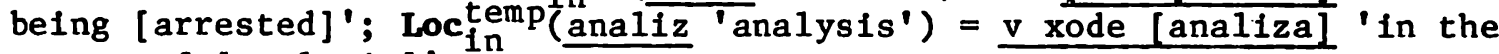
course of [analysis]'. 
36. Instr - a preposition [analogous to Loc] with the meaning of instrumentality: Instr(pistolet 'pistol') = iz [pistoleta], 11t. 'with [a pistol]'; Instr(mašinka 'typewriter') = na [mašnke] 'on [a typewriter]'.

37. Propt - a preposition with the meaning 'because of', 'as the result of': Propt(strax 'fear') $=$ ot [straxa], so [straxu] 'from [fear]'; Propt(1 jubov' 'love') $=$ iz [1jubvi k...] 'because of [one's love of ....]'; Propt(opyt I.1 'experience') = na [svoëm opyte] 'from [one's own experience]'.

38. Copul - a copula: Copul(uxitel' 'teacher') = byt', rabotat' [ưitelem] 'be, work as [a teacher]'; Copul(primer 'example') = byt', javljat'sja, sluzit' [primerom] 'be, represent, serve as [an example]'.

39. Pred - a verb meaning 'be $W$ ', i.e. semantically covering the syntactic combination of a Copul(w) with $W$. Thus Pred is nothing but a 'fused' expression of Copul( $W)+W$ (on 'fused' expressions see below) needed for the convenience of some synonymic transformations. For example, Pred(pjanica 'drunkard') = pjanstvovat' 'drink heavily', $\operatorname{Pred}\left(\underline{\text { rjadom }}\right.$ 'next to $\left.{ }^{\prime}\right)=$ sosedstvovat' $^{\prime}($ to $)$ neighbor'.

The next three LF's are verbs which are semantically empty in the context of the entry lexeme (1.e. their key word) and which serve to link, on the syntactic level, the name of a participant of a situation to $W$ - the name of the situation itself. They play important semantico-syntactic roles and can be loosely called semi-auxiliaries.

40. Oper $_{i}$ - the first deep actant (and the surface subject) of this verb is the i-th participant of the situation, and the second deep actant (or the first surface object) of Oper $_{i}$ is $W$ (further actants, if any, designate further participants of the situation); Oper $_{1}$ (slëzy 'tears') $=$ 1it', prolivat' 'shed'; Oper $_{1}$ (arest 'arrest') = proizvodit' 'make [an arrest]'; Oper 2 (arest 'arrest') = popadat' [pod arest] 'fa11 [under arrest]', podvergat'sja [arestu] 'undergo [arrest]'; Oper $_{1}$ (soprotivlenie 'resistance') = okazyvat' 'show, put up'; Oper $_{2}$ (soprotivlenie 'resistance') $=$ vstrečt' 'meet', natalkivat'sja [na soprotivienie] 'run [into resistance]'.

41. Func $c_{1}$ - the first deep actant (and the surface subject) of this verb is $\mathbf{W}$ - the name of the situation, and the second deep actant (and the first surface object), the i-th participant of the situation: Func $_{1}$ (udivlenie 'surprise, astonishment') = oxvatyvat', 1it. 'seize' [1.e. the person is overcome by surprise, astonishment]; Func $_{2}$ (temperatura 'temperature') $=$ ravnjat'sja 'be equal to'; Func $_{1}$ (predloženie 'proposal') = isxodit' [ot kogo-1.] 'stem from, come from [someone]'; Func 2 (predložnie 'proposal') $=$ kasat's ja [Cego-1.] 'concern [something]'. If there is no complement at all, 1.e. Func is

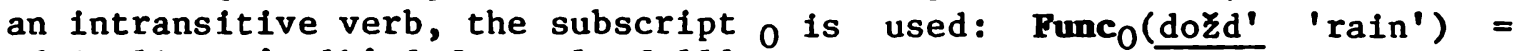
idti, 1it. 'walk' [cf. Engl. fall] 
42. Labor $_{i j}$ - the first deep actant (and the surface subject) of the verb is the 1-th participant of the situation; the second deep actant, the j-th participant of the situation; and the third deep actant (implemented by the second surface object) is $W$ itself. Examples: Labor $_{12}$ (dopros 'interrogation') = podvergat' [kogo-1. doprosu] 'subject [someone to an interrogation]'; Labor $_{32}$ (arenda 'lease') $=$ sdavat' [Cto-1. $v$ arendu] 'grant [something on lease]'.

Oper, Func, and Labor can be paired in converse relations, that is, Oper $_{1}=\operatorname{Conv}_{21}\left(\right.$ Func $\left._{1}\right) ;$ Labor $_{12}=\operatorname{Conv}_{132}\left(\right.$ Oper $\left._{1}\right)$, and so on. These relationships may be diagrammed as follows:

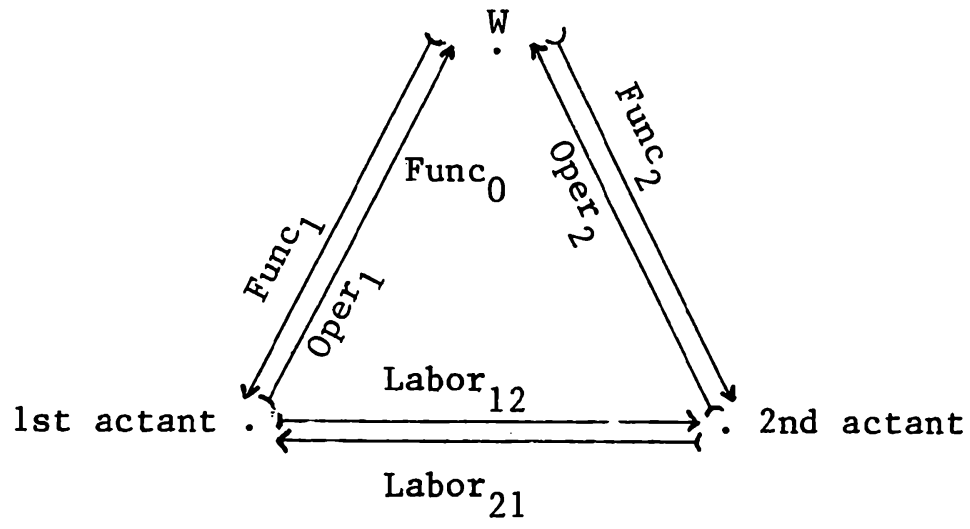

Here, a two-participant situation designated by key word $\boldsymbol{W}$ is presented. Arrows represent semi-auxiliary verbs; the arrow's tail indicates the surface (grammatical) subject, the head pointing toward the first surface object.

A different way to express the same idea is by using a matrix:

\begin{tabular}{|c|c|c|c|}
\hline Semi- $_{\begin{array}{l}\text { auxiliary } \\
\text { verbs }\end{array}}^{\text {Surface- }} \underbrace{}_{\text {roles }}$ & $\begin{array}{l}\text { Surface } \\
\text { subject }\end{array}$ & $\begin{array}{l}\text { First } \\
\text { surface } \\
\text { object }\end{array}$ & $\begin{array}{l}\text { Second } \\
\text { surface } \\
\text { object }\end{array}$ \\
\hline $\operatorname{Oper}_{1 / 2}$ & $\begin{array}{c}1 \text { st } / 2 \text { nd deep } \\
\text { actant of } w\end{array}$ & $\boldsymbol{H}$ & $-\infty$ \\
\hline Func $_{0 / 1 / 2 /}$ & $\mathbf{W}$ & $\begin{array}{l}\text { none/1st/2nd } \\
\text { deep actant } \\
\text { of } W\end{array}$ & -- \\
\hline Labor $_{12 / 21}$ & $\begin{array}{l}\text { lst } / 2 \mathrm{nd} \\
\text { deep actant } \\
\text { of } W\end{array}$ & $\begin{array}{c}2 \mathrm{nd} / 1 \mathrm{st} \\
\text { deep actant } \\
\text { of } W\end{array}$ & $\mathbf{W}$ \\
\hline
\end{tabular}


For instance, for 'A changes $B$ ' (in Russian) we have:

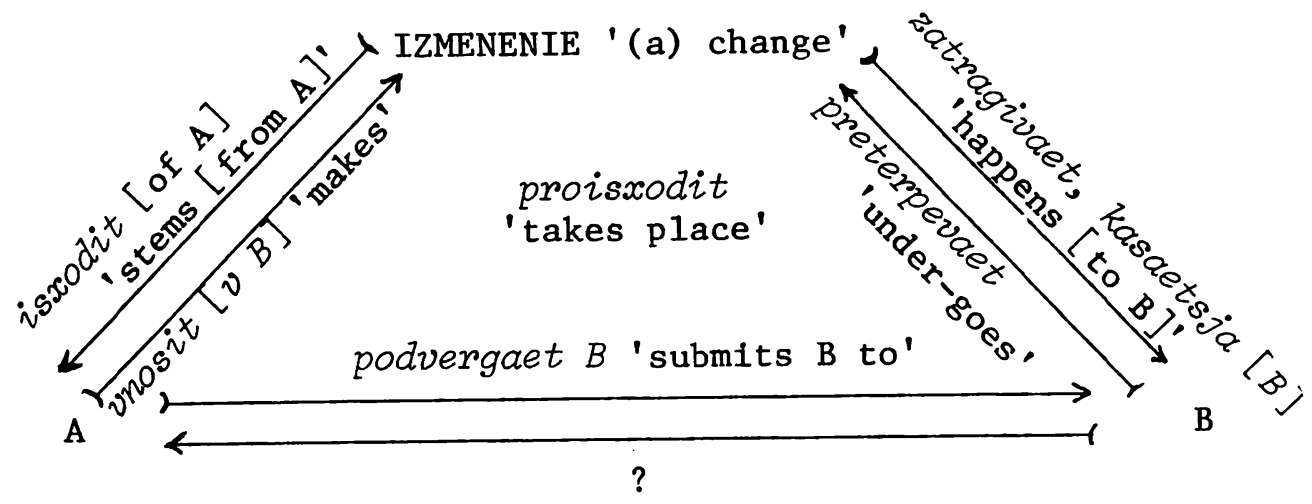

43. Involv - a verb that links a non-participant of a situation with the name of the situation acting on him: Conv 21 Involv(veter 'wind') $=$ stojat' [na vetru] 'stand [in the wind]'; IncepInvolv(metel 'snowstorm') = zastigat' 'catch'; A,Involv(metel' 'snowstorm') $=\underline{v}$ [meteli] 'in [a snowstorm]'.

44-46. The following three LF's represent the meanings of what are often called phasal verbs: Incep - 'begin'; Cont - 'continue'; Pin 'end, cease'. They are connected by obvious semantic relationships: $\operatorname{Fin}(P)=\operatorname{Incep}($ non $P) ; \operatorname{Cont}(P)=\operatorname{nonFin}(P)=\operatorname{nonIncep}($ non $P)$. Incep, Cont and Fin are used (at least in Russian) in combination with other LF's. Examples: Oper $_{2}$ (vlast' 'power') $=$ naxodit'sja [pod vlast'ju ....] 'be [under the power of ]', IncepOper ${ }^{\prime}$ (vlast $\left.^{\prime}\right)=$ popadat $^{\prime}$ [pod vlast'...]

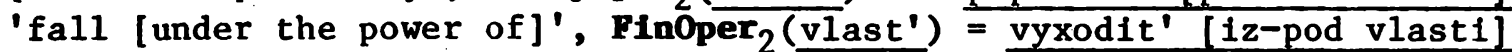
'get out . [from under the power of]'; Cont0per 1 (vlijanie 'influence') = soxranjat' 'maintain', Contoper 2 (vlijanie) $=$ ostavat's ja [pod vli janiem

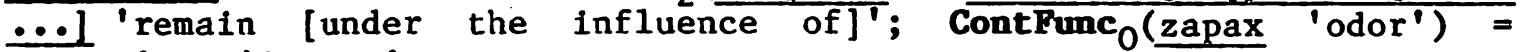
deržat'sja 'linger'.

47. Caus - 'cause', 'do something so that a situation occurs'. Caus is often used in combination with other verbal LF's. Examples: Causoper $_{1}$ (mnenie 'opinion') $=$ privodit' [kogo-1. $k$ mneniju] 'lead

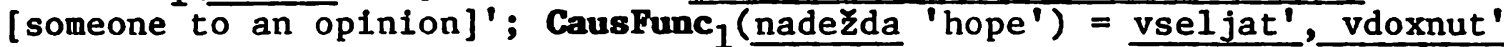
[nadezdu $v$ kogo-1.] 'raise [hope in someone], inspire [someone with

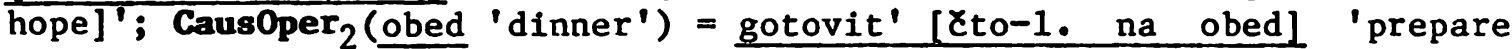
[something for dinner]'; CausFunc (obed) $^{\text {ogotovit', strjapat' [obed] }}$ 'make, cook [the dinner]'.

With the LF Caus, the LF's Perm and Liqu are naturally associated:

Liqu(P) $=\operatorname{Caus}($ non $P), \operatorname{Per}(P)=\operatorname{nonLiqu}(P)=\operatorname{nonCaus}($ non $P)$. Both Perm and Liqu are usually used in combination with other verbal LF's.

48. Perm - 'permit', 'allow': nonPermoper 2 (kritika 'criticism') = ograżat' [kogo-1. ot kritiki] 'protect [someone from criticism]'; 
Permoper $_{2}$ (èkzamen 'exam') = dopuskat' [kogo-1. $\mathrm{k}$ èkzamenu] 'allow [someone to (take) an exam]'.

49. Liqu - 'Iiquidate', 'do something so that a situation does not occur or stops occurring': LiquFunc ${ }_{0}$ (negramotnost' 'illiteracy') = pokon'it' [s negramotnost' ju] 'wipe out [111iteracy]'; Liqu Func $_{0}$ (kostër 'campfire') = potusit' [kostër] 'extinguish [a campfire]'.

50-52. Now let us look at another triple of interrelated LF's: Real $_{i}$, Fact $_{i}$ and Labreal $_{1 j}$ •

The LF's Real $_{1}$, Fact $_{i}$, and Labreal ${ }_{i j}$ are syntactically analogous to the functions Oper $_{i}$, Func $_{1}$ and Labor ${ }_{1 j}$, respectively. This means that the names of the situation and of its i-th participant fulfill with respect, for example, to Real $_{i}$ the same syntactic roles as they do with respect to Oper $_{i}$; etc. However, unlike the "empty" LF's Oper , $_{i}$ Punc $_{i}$, and Labor $_{i j}$, the lexical functions which we are now concerned with correspond to a specific meaning: 'fulfill a demand or requirement of ...'. The demands can differ for different $W^{\prime} s$. For example, the fulfillment, or realization, of a hypothesis is its confirmation; therefore, Real 2 (gipoteza 'hypothesis') = podverždat' 'confirm' [Fakty podtverždajut gipotezu 'The facts confirm the hypothesis'], and Fact $_{2}$ (gipoteza 'hypothesis') = sootvetstvovat' 'be in accordance with [Gipoteza sootvetsvuet faktam The hypothesis is in accordance with the facts']. Realization of an artifact is its utilization according to its intended function; therefore, $\operatorname{Fact}_{0}$ (noz 'knife') = rezat' 'cut' [Etot noz režet xorošo 'This knife cuts well']• Further examples:'

Real $_{1}$ (obvinenie 'accusation') = dokazyvat' [obvinenie] 'prove [an accusation]'; Real (urebnoe zavedenie 'educational institution') = prepodavat' [v uxebnom zavedenii] 'teach [in an educational institution]'

$\operatorname{Real}_{2}$ (obvinenie) $=$ soglašat'sja [s obvineniem] 'agree [with an

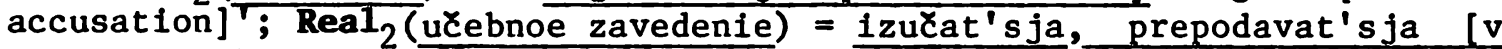
urebnom zavedenii] 'be studied, be taught [in an educational institution]' (while Real $_{3}$ (uČebnoe zavedenie) = uX̌it's ja [v uXebnom zavedenii] 'study [in an educational institution]'); Real $_{2}$ (soblazn 'temptation') = poddavat's ja [soblaznu] 'yield [to temptation]'.

Fact $_{0}$ (somnenie 'doubt') = podtverždat'sja 'be confirmed',

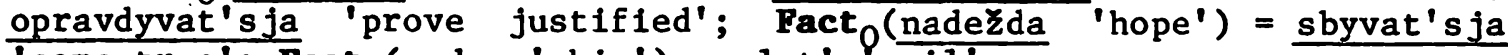

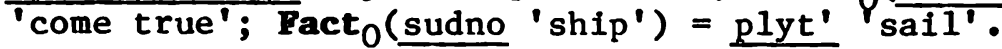

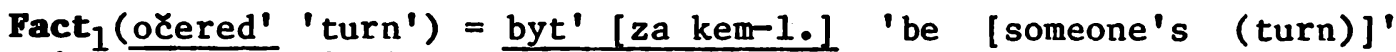
[orered' za vami 'It's your turn']; Fact $_{1}$ (èksperiment 'experiment') = udavat's ja [komu-1.] 'work out [for someone]'.

Fact $_{2}$ (sudno1 'ship') = vezti, perevozit' [gruzy, passažrov]

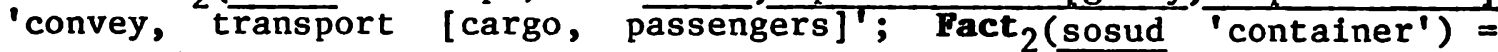
soderžat' [Cto-1.] 'contain [something]'. 
Labreal $_{12}$ (viselica 'gallows') = vzdernut' [kogo-1. na viselicu] 'string up [someone on a gallows]'; Labreal 12 (obed 'dinner') = est' [Cto-1. na obed] 'eat [something for dinner]'.

The LF's Real $i$ Fact $_{i}$, and Labreal $i j$ can be superscripted with Roman numerals to indicate the degree of the realization or fulfillment: the superscript I means fulfillment only at the psychological level, with the superscript II meaning fulfillment at the physical level, cf. Real I (priglasenie 'invitation') = prinimat' 'accept', while

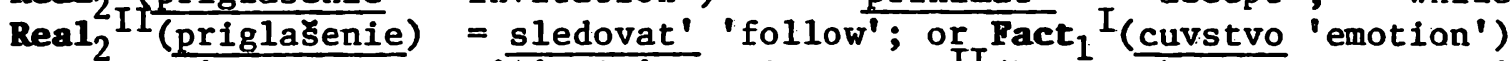
$=$ govorit', podskazyvat' 'tell', while Fact $_{1}$ II (Euvstvo) $^{\prime}$ ' zastavl jat' 'force'.

53. Manif - 'manifest itself', 'become apparent': Manif(vina 'guilt', 'fault') = obnaruživat's ja 'become apparent'; Manif(udivlenie 'amazement') $=$ skvozit' '1urk'; Manff(bezgramotnost' 'ignorance') = projavljat's ja 'manifest itself'.

Sympt - 'symptom', i.e. a verbal expression denoting a bodily reaction that is the symptom of an emotional or physical function: Sympt(udivlenie 'amazement', glaza 'eyes') $=[U$ negol glaza na lob polezli '[His] eyes started from his face'; Sympt(udivlenie 'amazement',

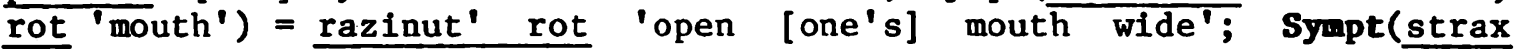
'fear', volosy 'hair) = [U nego] volosy vstali dybom '[His] hair stood on end'.

55. Prepar - 'prepare', 'get (something) ready for normal use or

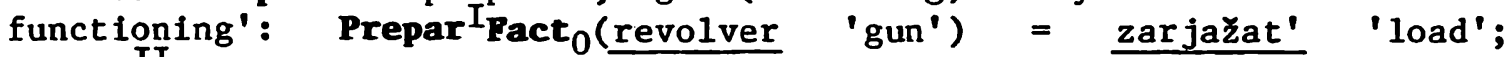

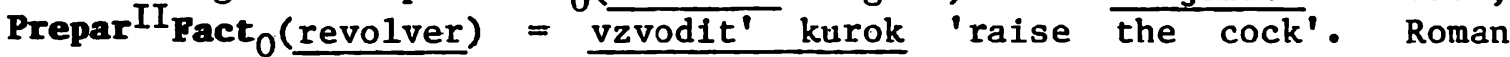
superscripts, in much the same manner as with Real $_{i}$, Fact $i$, and Labreal $_{i j}$, express the degree of readiness. Compare also: Preparoper $_{1}$ (obed 'dinner') = vyxodit' [k obedu] 'appear [for dinner]'; Preparoper $_{2}($ obed $)=$ podavat' [na obed] 'serve [something for dinner]'; PreparFunc $_{1}(\underline{\text { obed }})=$ podavat' [obed komu-1.] 'serve [somebody dinner]'.

56. Prox - 'be about to / on the verge of': Proxoper (otcajanie $^{\text {(ota }}$ 'despair') = byt' na grani [otxajanijal 'be on the edge of [despair]'; Proxfunc $_{0}$ (groza 'thunderstorm') = sobirat'sja 'gather, brew'.

57. Degrad - 'degradation', 'become worse or bad': Degrad(moloko 'milk') = skisnut' 'go sour'; Degrad(mjaso 'meat') = protuxnut' 'go bad'; Degrad(disciplina 'discipline') = 'decay'.

58. Son - 'emit characteristic sound': Son(sobaka 'dog') = lajat' 'bark'; Son(banknoty 'banknotes') = xrustet' 'rustle'; Son(sneg

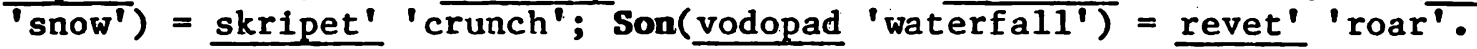

59. Imper - 'do W!': Imper(streljat' 'shoot') = ogon'! 'fire!'; Imper(brat' oružie 'seize arms) $=\underline{v}$ ruž'ë! 'take up arms!'; 
Imper(govorit' tixo 'speak lowly') = ts-s-s!, ţ-s-s! 'sh-h-h'; Imper( brat' $^{\prime}$ take' $\left.^{\prime}\right)=$ na (te)! 'take $1 t !$ ', 'here!'

60. Perf - 'perfective', i.e. 'have the process carried through to its natural limit': Perf(vstavat' 'be standing up') = vstat' 'have stood up'; Perf( solved'.

61. Imperf - 'imperfective', i.e. 'be carrying out the process': $\operatorname{Imperf}\left(\right.$ vstat $\left.^{\prime}\right)=$ vstavat'; $^{\prime}$ Imperf $\left(\right.$ rešt $\left.^{\prime}\right)=$ resat $^{\prime}$.

62. Result - 'resultative', i.e. 'the state of affairs that normally results from the completion of the process': Result(pokupat' 'buy') = Imet' 'have'; Result (1ožtt'sja 'lay down') = ležat' 'be lying'; Result(nauxit'sja 'have learnt') = umet' 'know', 'have necessary $\therefore 111 s^{\prime}$. 


\section{Appendix B: Three sample dictionary entries}

In order to give the reader the full taste of an ECD, we will quote two dictionary entries, one Russian and one French (from Mel'ruk and Zholkovsky 1984: 651-653 and Mel'Cuk et al. 1984: 148-149, respectively). These are the lexemes predlozenie ${ }^{1} 1 a, b$ and proposition 1 , both meaning roughly 'proposal' = 'the act of proposing or what is being proposed' and being approximate equivalents under translation.

The entries are reproduced here with slight modifications aimed at facilitating comparison. Since we address ourselves to an English-speaking audience, both actual metalanguages (Russian and French) have been replaced by English. We are not in a position to explain all the details of presentation; but we hope they will become clear in due course.

For the benefit of English readers, we add also an English lexical entry written by James Steele (Carleton University, Ottawa) and heavily edited by the author with the help of David Weber and David Tuggy (Summer Institute of Linguistics, Grand Forks, North Dakota). It is the first sense of the noun hope II (hope I being the verb).

\section{SAYPLB 1: RUSSIAN}

Russ. PREDLOZENI $\mid \mathrm{B}^{1}$, ja, ja, neuter

1a,1b. Predloženie X-a [Z-u] delat' Y 'Proposal by X [to Z] to do $Y^{\prime}=$ 'What is (being) proposed by $X$ to $Z$ ' [ $=S_{2}$ (predlagat' $1 a, 1 b$ or predlozit' la,1b].

Government Pattern

\begin{tabular}{|l|l|l|}
\hline $1=\mathrm{X}$ & \multicolumn{1}{|c|}{$2=\mathrm{Y}$} & $3=\mathrm{Z}$ \\
\hline 1. $\mathrm{N}_{\text {gen }}$ & 1. $\mathrm{N}_{\text {gen }}$ \\
2. ot $\mathrm{N}_{\text {gen }}$ & 2. $\mathrm{V}_{\text {inf }}$ \\
3. A & 3. $\frac{\text { Ctoby }_{\text {poss }}+}{\text { PROPOS }}$ \\
4. A & \\
\hline
\end{tabular}

1) $C_{1.2}$ : only with LF Result Rd $_{3}$ and $\operatorname{Conv}_{21}$ Result $_{3}$ 
2) $\mathrm{C}_{1.4}: \mathrm{A}=\mathrm{A}_{0}(\mathrm{~N})$, where $\mathrm{N}$ is the name of a country

3) $\mathrm{C}_{2.1}$ : only for PREDLOŽENIE ${ }^{1} \mathrm{la} ; \mathrm{N}$ is a predicate

4) $C_{1.1}+C_{2.1}:$ impossible

$\mathrm{C}_{1} \quad$ : predloŽenie Petra 〈Francil〉 'proposal by Peter 〈France〉', [Ja Imeju] predlozenie ot direktora '[I have] a proposal from the director', naši 〈francuzskie〉 predloženija 'our 〈French〉 proposals'

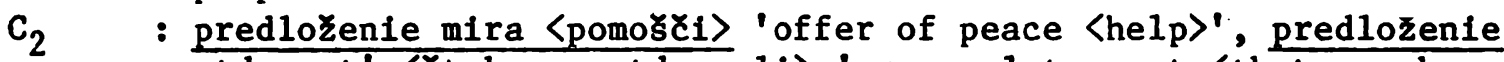
otdoxnut' 〈xtoby my otdoxnuli〉 'proposal to rest 〈that we have

$C_{1}+C_{2}$ : americanskoe predloženie pomošct 'American offer of help', predlozenie brigadira otdoxnut' 〈rtoby my otdoxnuli) 'the proposal by the brigade chief to rest (that we have a rest)'

Impossible: *Menja tronulo predloženie pomošri ot Koli 'I was moved by the offer to help from Kolya (1) $[=$ Menja tronulo Kolino predloženie pomoši ; but cf. U menja est ${ }^{\prime}\left[=\operatorname{Conv}_{21}\right.$ Result $_{3}$ ] predloženie pomoši ot Koli 'I have an offer of help from Kolya']; *moskovskoe predloženie 'Moscow proposal' (2) [ predloženie Moskuy]; ‘predloženie otdyxa 〈knigi〉 'proposal/ offer of rest 〈of a book>' (3); 'predloženie Peti pomoši 'offer of help by Pete' (4)

\section{Lexical Punctions}

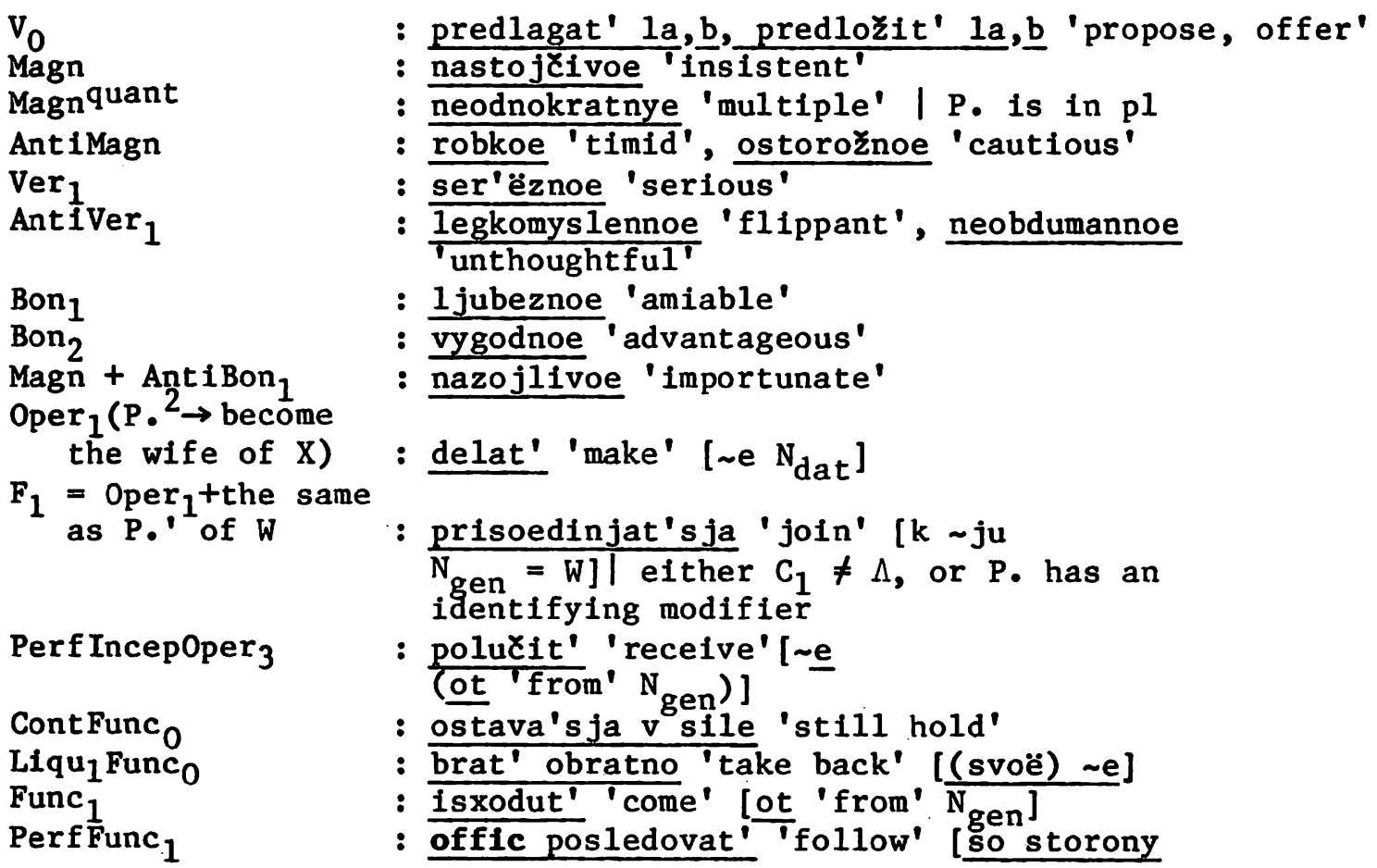


Func,

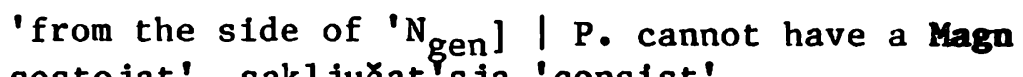
: sostojat', sak1jutat's ja 'consist' [v 'in' ${ }_{\text {prep }}$ '

\section{Exanples}

Ona otvetila otkazom na ego robkoe predloženie pomox' ej 'She answered with a refusal to his shy proposal to help her'. Po predloženiju xozjajki my ostalis' ešë na dva dnja 'Following the proposal of the lady of the house, we stayed two more days'.

\section{SAMPLE 2: FREITCH}

Fr . PROPOSITION ${ }^{1}$, feminine

1. Proposition de $X$ a $Z$ de Ye $r$ 'Proposal by $X$ to $Z$ to

do $Y^{\prime}=$ 'Fact that $X$ proposes $Y$ to $Z$ or the message concerning $Y$ by means of which $X$ proposes $Y$ to $Z^{\prime}\left[=S_{0} / S_{2}\right.$ (proposer 1 )]

\section{Government Pattern}

\begin{tabular}{|l|l|c|}
\hline $1=\mathrm{X}$ & \multicolumn{1}{|c|}{$2=\mathrm{Y}$} & $3=\mathrm{Z}$ \\
\hline 1. de $\mathrm{N}$ & 1. de $\mathrm{N}$ & $1 \cdot \underline{\mathrm{a}} \mathrm{N}$ \\
2. Aposs & $2 \cdot$ de $\mathrm{V}_{\text {inf }}$ & \\
3. A & 3. que PROP subj & \\
\hline
\end{tabular}

1) $\mathrm{C}_{1.3}: \mathrm{A}=\mathrm{A}_{0}(\mathrm{~N})$, where $\mathrm{N}$ is the name of a country, or $\mathrm{N}=$ patron, gouvernement, ...

2) $\mathrm{C}_{2.3}: \mathrm{M}_{1}=\mathrm{M}_{1}(\mathrm{Y})$

3) $c_{3}$ without $C_{1}$ or $C_{2}$ : not desirable

$\mathbf{C}_{1}$

$\mathrm{C}_{2}$

: la proposition de Pierre 〈de la France〉

'proposal by Peter 〈France〉, notre proposition

'our proposal', les propositions françaises

'French proposals'

: la proposition de paix 〈d'aide〉 'proposal

of peace 〈help', la proposition d'apporter de

l'aide 'proposal to give some help', la

proposition que son valet fasse cela 'proposal

that his servant do that'

$c_{1}+c_{2}+c_{3}:$ travail a Marie 'his 〈the French〉 proposal of work to Mary', sa proposition <la proposition française> a Marie de participer au tournoi 'his 
〈the French> proposal to Mary to participate at the tournament', la proposition d'argent de Pierre a Marie 'proposal of money by Peter to Mary'

Lot desirable: ? 1 a proposition à Marie (3) $[=1$ a proposition faite a Marie 'the proposal made to Mary']

\section{Lexical Functions}

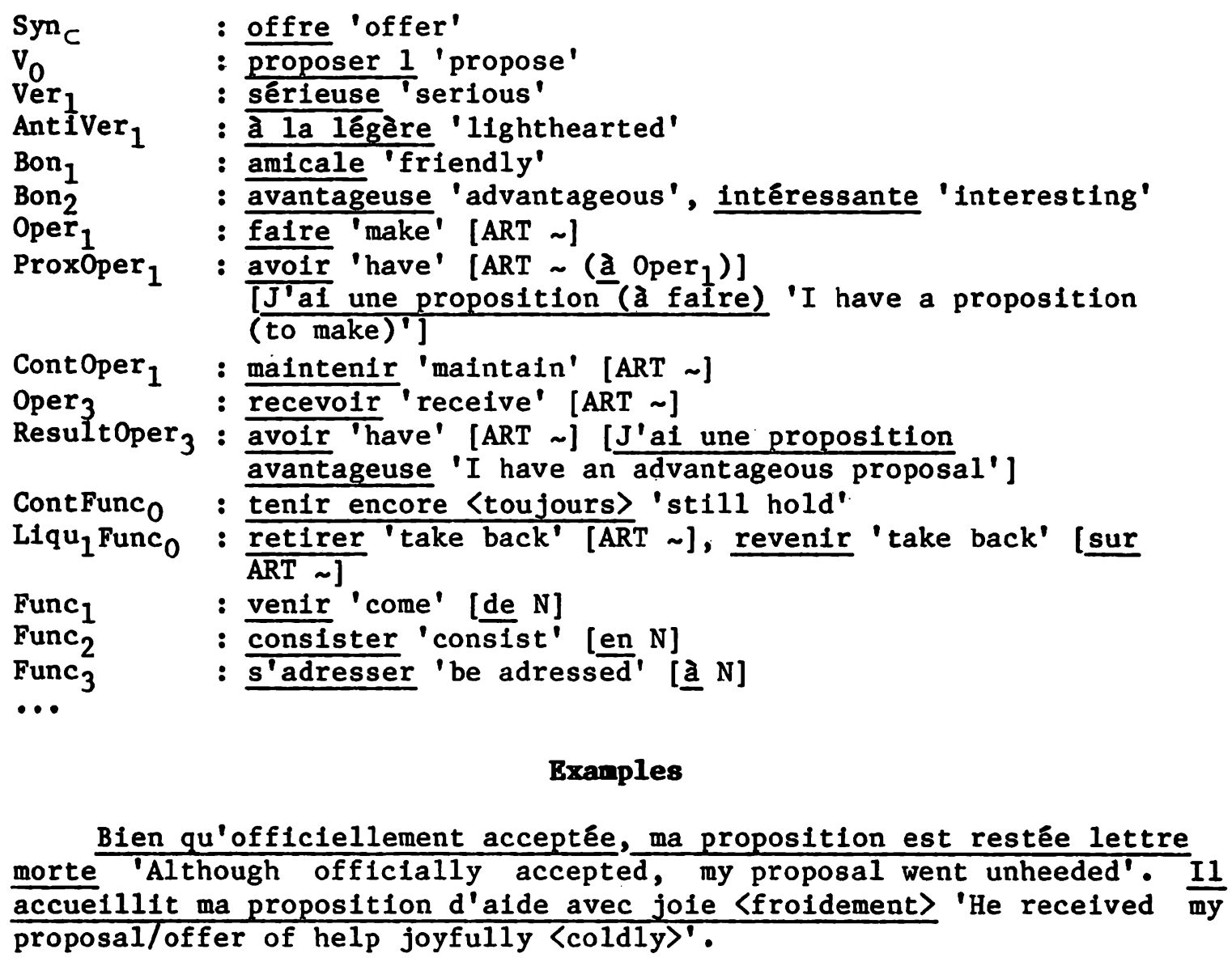

\section{Exanples}

Bien qu'officlellement acceptée, ma proposition est restée lettre morte 'Although officially accepted, my proposal went unheeded'. Il accuellilt ma proposition d'alde avec joie 〈froidement> 'He received my proposal/offer of help joyfully $\langle\operatorname{coldly}\rangle^{\prime}$.

SAYPLE 3: BNGLISH

II. HOPE, noun

1. X's hope of $Y=S_{0}$ (hope I.1). 
Government Pattern

\begin{tabular}{|l|l|}
\hline $1=\mathrm{X}$ & $2=\mathrm{Y}$ \\
\hline 1. of $\mathrm{N}$ & 1. for $\mathrm{N}$ \\
2. N's & 2. of $\mathrm{N}$ \\
3. A poss & 3. of $\mathrm{V}$ \\
& $\begin{array}{l}\text { 4. to } \mathrm{Vger} \\
\text { Inf }\end{array}$ \\
& 5. that PROP \\
\hline
\end{tabular}

N.B.: The plural [ s] can be used in the singular sense with $C_{2.3,4}$ and, if $\mathrm{N}$ is singular, with $\mathrm{C}_{2.1,2}$ [His hopes $=$ hope> of winning the lottery prize died when his number was not drawn; He bought ten tickets for the lottery in hopes « $=$ hope> of winning the prize].

1) $\mathrm{C}_{1.1}+\mathrm{C}_{2.2}$ : not desirable

$c_{1} \quad:$ the hope of Peter, Peter's $\langle$ his $\rangle$ hope

$\mathrm{C}_{2} \quad$ : hope for 〈of> victory, hope of winning 〈to win> a victory, hope that victory would be won

$\mathrm{C}_{1}+\mathrm{C}_{2} \quad:$ Peter's 〈his〉 hope of being successful 〈to be a success>, the hope of Peter 〈his hope〉 that success would be achieved

Not desirable: ' the hope of Peter of success $(1)=$ Peter's hope of success

Lexical Functions

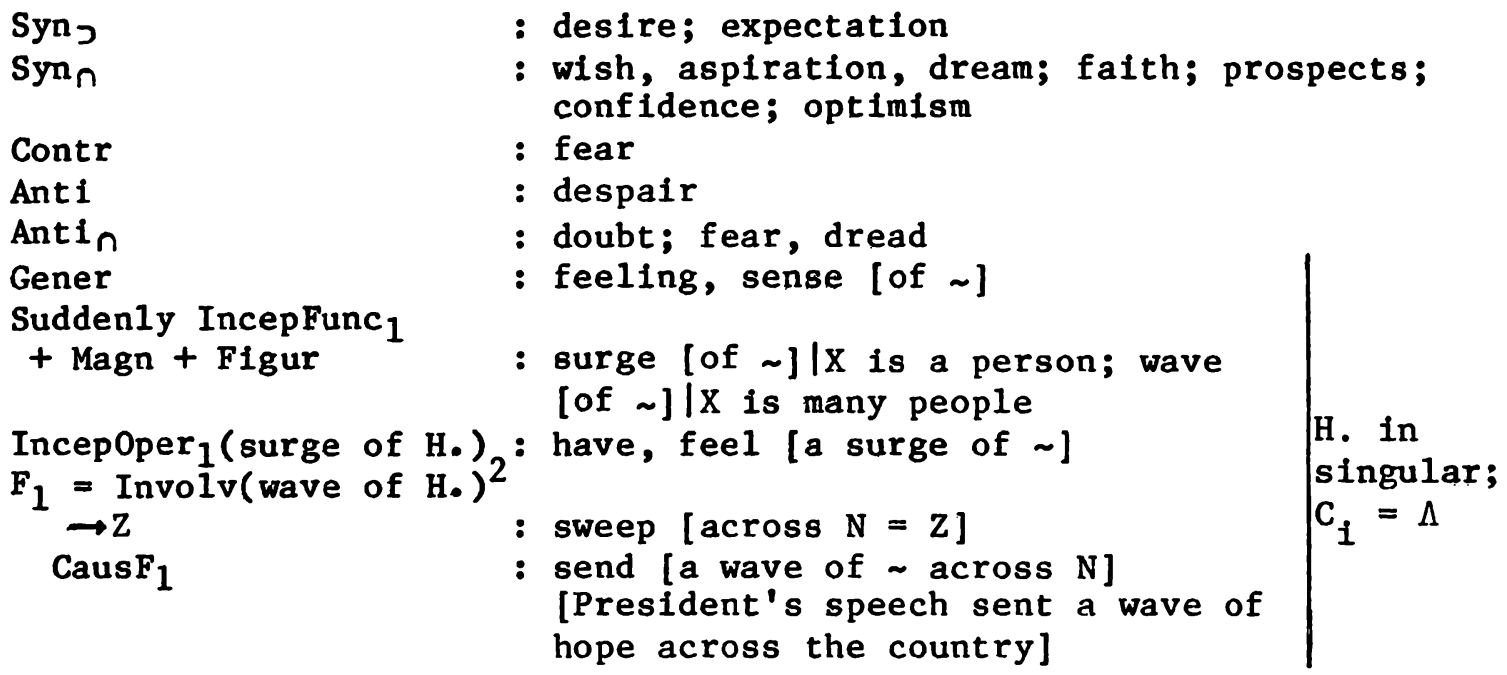




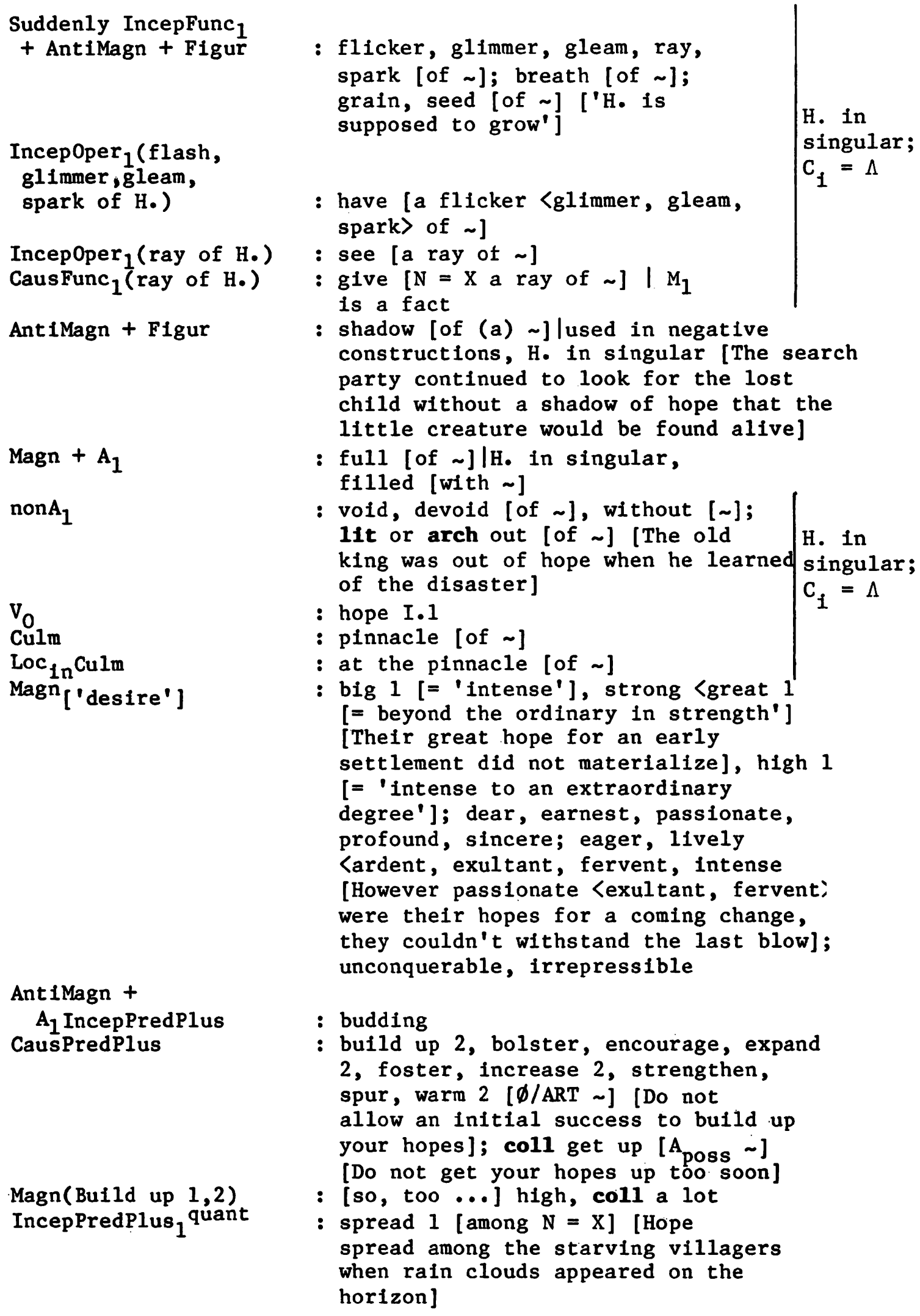




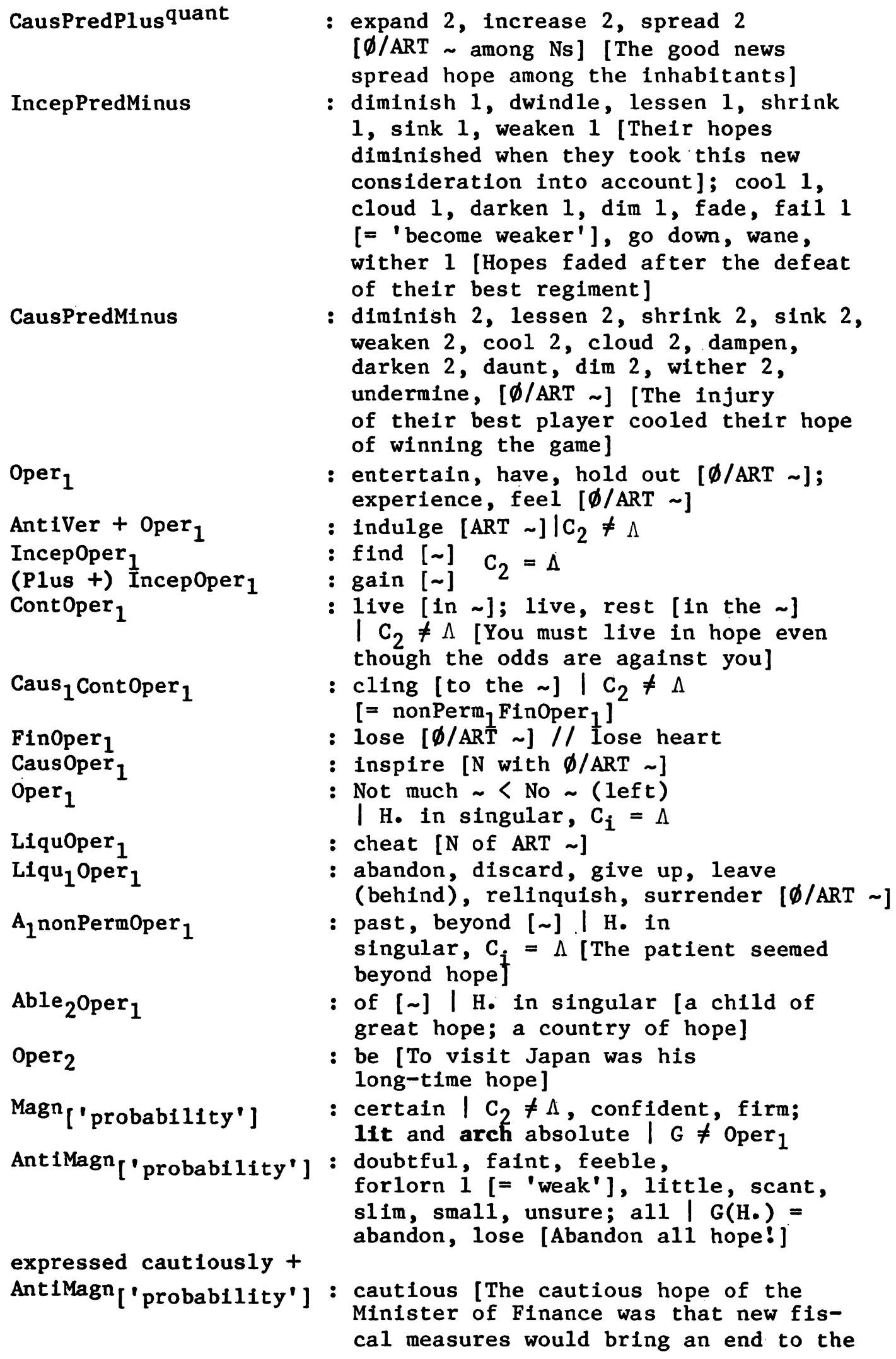




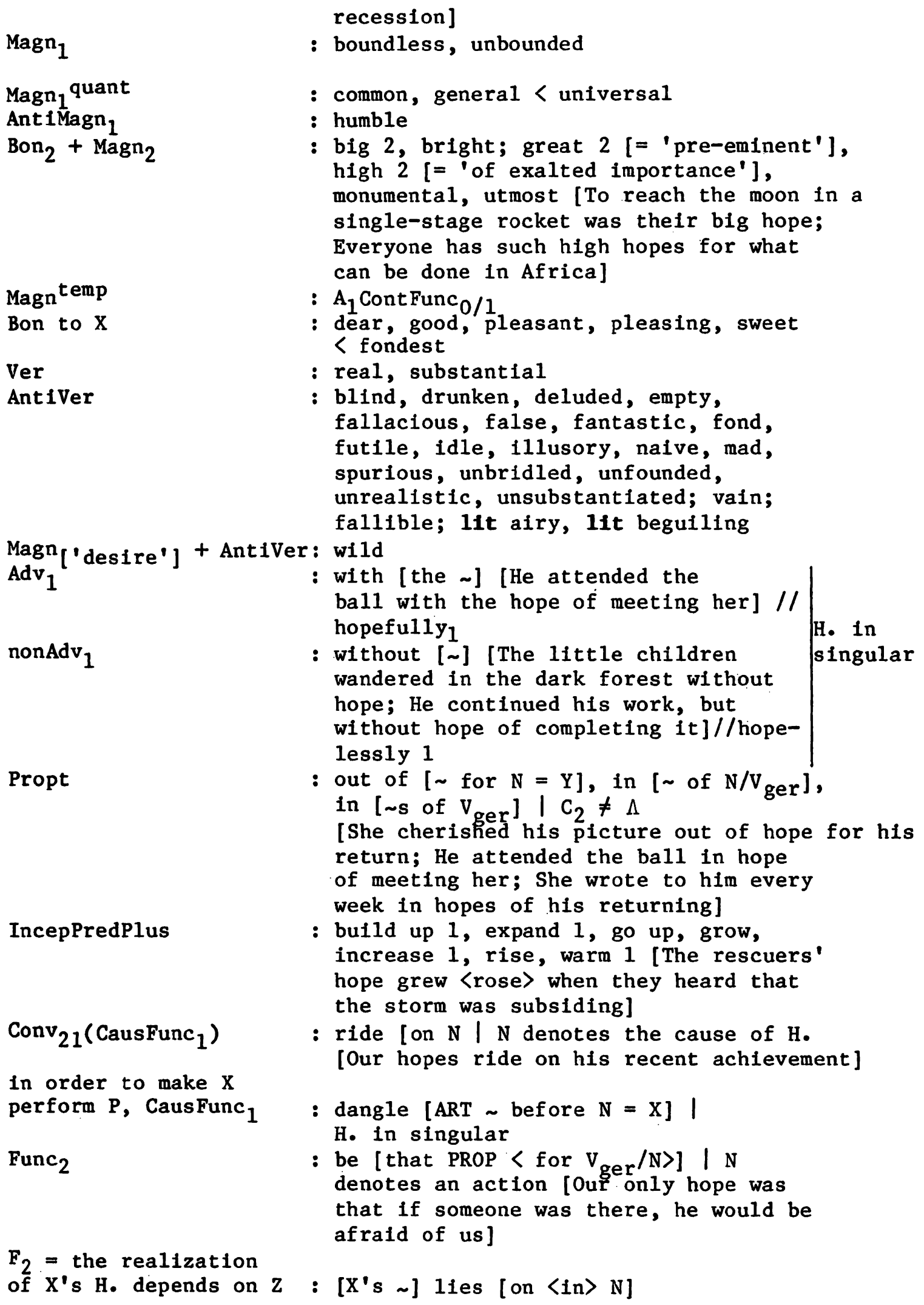




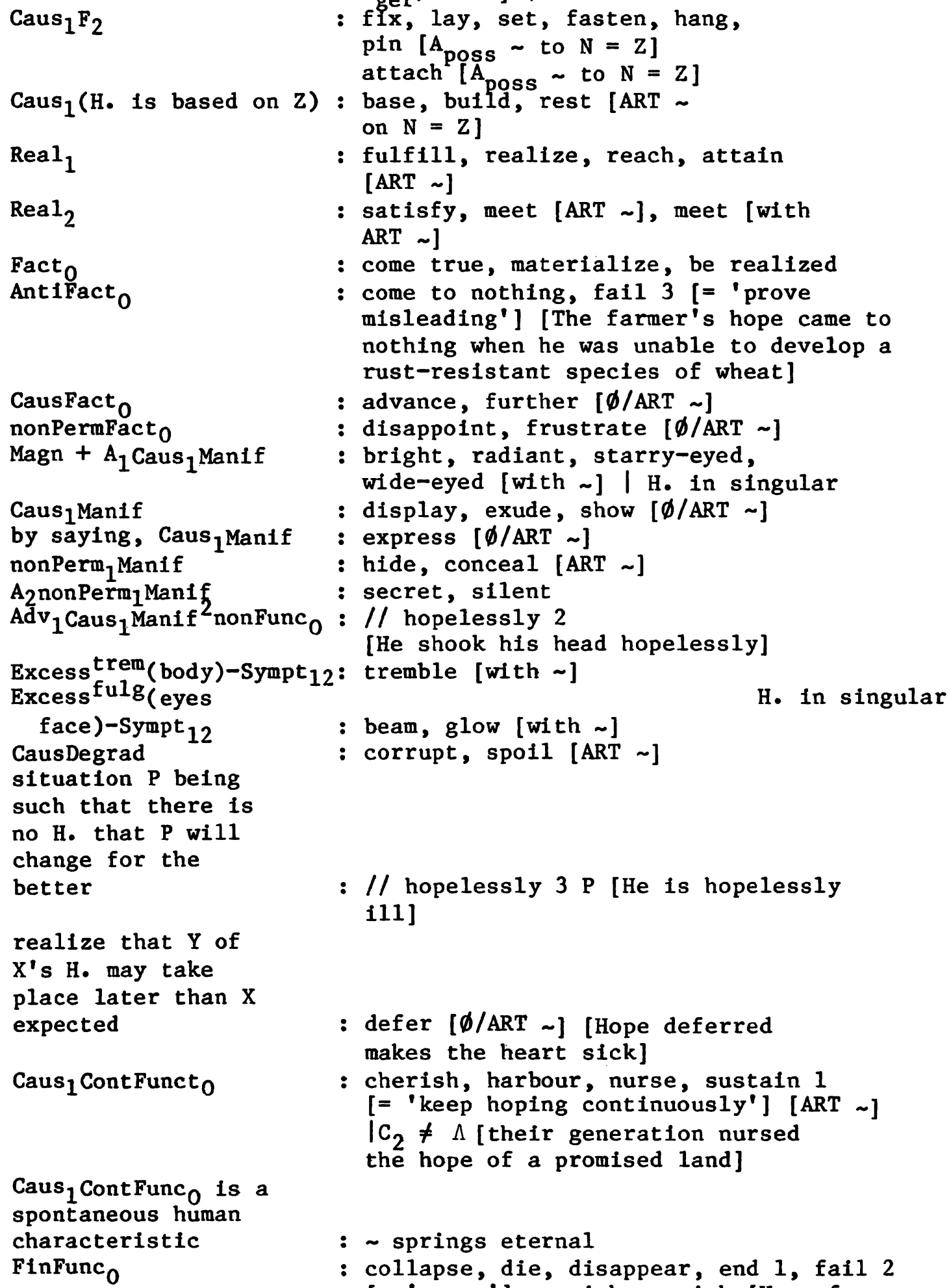

: // hopelessly $3 \mathrm{P}$ [He is hopelessly il1]

: defer [ $\emptyset /$ ART ] [Hope deferred makes the heart sick]

: cherish, harbour, nurse, sustain 1 [= 'keep hoping continuously'] [ART ] $\mid C_{2} \neq \Lambda$ [their generation nursed the hope of a promised land] 
PerfFinfunc $_{0}$

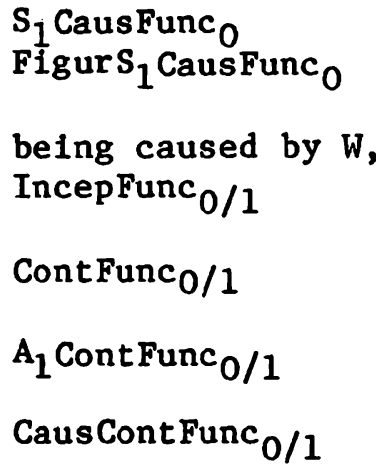

LiquFunc $_{0 / 1}$

Func $_{1}$

IncepFunc $_{1}$

again IncepFunc ${ }_{1}$

nonPermContFunc $_{1}$

Finfunc 1

CausFunc $_{1}$

again CausFunc $_{1}$

live disregarding adverse facts or material necessities as if the $H$. of $X$ lasting peace collapsed with the renewed fighting]

: be gone, be finished, be extinct, be at an end; be dead [Our hope for life on Mars is dead]; lit or arch be done

: source [of $\sim$ ]

: star, beacon, well-spring, bastion [of $\sim$ ] I H. in singular

: arise, be born [in $N<N^{\prime}$ s soul, heart, breast $>$ ]

: linger, persist, remain [in $\mathrm{N} /$ among Ns ]

: enduring, lasting, persistent, steadfast, bibl unfading

: feed, keep alive, nourish, sustain 2 [=' 'give strength to hopes'] [Good news from the front fed the hopes of the general]

: crush, demolish, destroy, wreck [ $\varnothing /$ ART ] ; cut off [A poss $\sim / \mathrm{N}$ from ]; blast, blight, break, dash, end 2, extinguish, kill, ruin, shatter, take away, trample down [ART ] [The mother's hopes were shattered by the death of her young son]; bury, drown [ $\phi /$ ART $\sim$ ] $\mid M_{1}$ denotes a fact

: there be [in N's soul <heart, breast,...$>]$

: spring [in $N^{\prime}$ s soul <heart, breast, ...> ]

: return [to N], revive 1 [in $\mathrm{N}$ ] [Hope revived in her]

: leave [N 1ittle $\langle n o\rangle \sim$ ] [It leaves him no hope of escape]

: abandon [N]

: arouse, awaken [ ]; raise [The serious negotiations raise hopes for an early end to the strike]; stir up [ $\phi / \mathrm{ART} \sim$ in $\mathrm{N}]$; engender, instill, plant [ $\varnothing / \mathrm{ART} \sim$ in $\mathrm{N}$ ] $\mid \mathrm{H}$. in singular; give, hold out, offer [ $\varnothing /$ ART to N] i H. in singular

: restore, revive 2, reawaken, rekindle [ $\varnothing /$ ART ] [Warm weather restored the hope of the farmers] 
constituted reality

or a means of $X^{\prime} s$

sustenance
: live [on ] [Despite a fatal diagnosis, the young man continued to live on hope; After all food was consumed, the explorers lived on hope]

\section{Examples}

Man is a victim of dope, in the incurable form of hope. (0.Nash) It was evident to everyone that a strong sense of hope was the guiding power in her life. A light of hope shone in their eyes when they heard the good news. Rising popularity in pre-election polls gave the new party a ray of hope. The discovery of penicillin opened a door of hope for the wounded. The children were full of hope after visiting Santa Claus. The young man was devoid of hope when he learned the sad fate of his brother. She was suddenly killed while at the pinnacle of hope. To feed the poor was the dear hope of the good monk. An ardent hope of victory is what encouraged the competitors to do their best. Inspired by certain hope of success, the hunter continued his search. They had but faint hope that the buried miners would be found alive. The children had boundless hopes that they would excel in the examination. The common hope was for a bountiful harvest. Their best hopes were unmercifully shattered by the death of their son. Throughout their sinful lives, they were inspired by the sweet hope of redemption. Only substantial hopes should be taken into consideration by the committee. He was always preoccupied with empty hopes. Driven to extremes by her wild hopes, she finally committed suicide. When the soldier heard of the great victory at the front, his hopes for an end to the war went up. The woman's budding hopes grew stronger when she received the happy letter from her friend. The silly man indulged the hope that he could write a novel in three days. The sick man gained hope when he learned of the new medicine that might cure his illness. The workers found new hope in their revolution. The young child clung to the hope that her dead father would come back to life. Hope for a solution to the problem must be deferred until better conditions prevail. When the radio finally went silent, the operators in the control tower lost all hope. A happy turn of events inspired the men with hope. Stormy weather cheated the fishermen of their hope for a large catch. Our hopes now lie in the skill of the surgeon. The great drought left them little hope for a good crop. Once the oil slick was found on the surface of the water, all hope for the submarine was gone. Hope for a new life was born in John's soul after he read the Bible. Despite initial losses, hope for an early victory lingered. Winning the hand of a certain lady was the romantic gentleman's steadfast hope. The long drought destroyed the hope of the farmer for a good harvest. Lack of financial resources cut off his hopes. The young lover walked down the path, hope springing in his heart. After the war, hope for economic progress returned. The serious negotiations stirred hopes for an early end to the strike. Let us instil in our children hope for a better world. The physician could not hold out much hope to his 
patient. The coach's hopes for his team rode on their recent achievement. The Minister of Housing dangled the hope of interest-free loans before builders. The young man pinned his hope (of quick success (for this marriage>) on finding steady employment. The newly elected Prime Minister was a source of hope to many citizens. Medicare was their beacon of hope. Do not hang your hopes on impossible schemes if you wish to avoid disappointment. Despite the dense fog, the explorers never gave up hope of finding their way back to their camp. The young bride clung to the hope that her spouse would return from the war alive. Unconquerable hope guided the romantic poet. In composing a great symphony, the musician realized a boyhood hope. The farmer's hopes came true after he developed a species of wheat that was resistant to rust. Development of the electrical automobile advanced the car manufacturers' hopes for success. Adverse economic conditions frustrated hopes of achieving a low rate of unemployment. She was radiant with hope after being nominated a candidate for office. An optimist will display hope even in adversity. The fisherman expressed hope for a good catch. The villain concealed a hope that the plane would crash with his mother on board. The silent hope of the innocent victim was her ultimate vindication. When the evangelist touched the sick woman, she trembled with hope. The children were glowing with hope on Christmas Eve. No adversity will corrupt our hope.

\section{Notes}

I am happy to express my heartfelt gratitude to Lidija Iordanskaja, who, as always, was the first to read the text of my paper and suggest many important corrections and improvements, and to Peter Constable, Ingrid Meyer and James Steele, who kindly accepted the task of revising the English of the manuscript.

A part of this paper was presented as key-note address at the 1985 annual meeting of the Linguistic Association of Canada and the United States (LACUS), in Saskatoon, Saskachewan, Canada.

1. We make use of the distinction avaflable in German:

$$
\begin{gathered}
\text { sprachlich 'pertaining to or related to language', } \\
\text { sprachwissenschaftlich 'pertaining to or related } \\
\text { to linguistics' }
\end{gathered}
$$

We use the English word 'linguistics', therefore, only when the second meaning is intended, and the German sprachlich when the first meaning is intended.

2. The primacy of the speaker's viewpoint for linguistics is so fundamental an issue that it seems recommendable to analyze here an interesting argument against it, advanced by Thomas R. Hofmann. The argument runs approximately as follows:

Within the framework of "good" communication, the speaker has to make sure that he is properly understood; and to achieve 
this, he must put himself in the addressee's shoes, that is, try to decode all his own utterances and see whether they can be interpreted the way he intends them to be. Therefore, the speaker must use listener's device as well, with the result that the task of speaking is harder than that of understanding.

The reasoning is quite sound -- but it misses the point. Certainly, the speaker has to use a listening (= understanding) device, but it by no means follows from this fact that the speaking device is more complex than the listening one. The task of a speaker in a communication act may be harder than that of his listener; we do not, however, compare communication tasks, but rather mechanisms correlating meanings and texts (leaving aside mechanisms for constructing meanings, for backtracking what has been said, etc. - mechanisms that are extremely important in "sprachlich" communication but do not pertain to language and are, consequently, of no interest for linguistics).

3. The logico-semantic concepts predicate, place (of a predicate) and argument are central to the present discussion, but we are in no position to introduce them here. We assume our readers' familiarity with them and limit ourselves to a warning against confusing predicate in logico-semantic sense (= 'a meaning having obligatory slots for other meanings') with the grammatical term predicate (= 'main verb'). Likewise, place (='a slot of a predicate') and argument (= 'meaning filling the slot of a predicate') should not be taken in their everyday sense.

4. For lack of space, we cannot even touch here upon the fundamental problem of semantic primitives.

5. Once again, we are not in a position to substantiate here the use of purely distinctive (= meaningless) symbols instead of meaningful labels on the arcs.

6. Interesting examples of values of the LF Mult in English can be found, most unexpectedly, in The Book of Lists, by D. Wallechinsky, I. Wallace and A. Wallace, New York: W. Morrow, 1977, page 135:

$\begin{array}{ll}\text { A murder } & \text { of } \\ \text { clowder } & \text { cats } \\ \text { leap } & \text { leopards } \\ \text { sloth } & \text { bears } \\ \text { raffer } & \text { turkey } \\ \text { smack } & \text { jellyfish } \\ \text { skulk } & \text { foxes } \\ \text { labor } & \text { moles } \\ \text { crash } & \text { rhinoceros } \\ \text { siege } & \text { herons } \\ \text { rag } & \text { colts } \\ \text { drift } & \text { hogs } \\ \text { charm } & \text { finches }\end{array}$




$\begin{array}{ll}\text { trip } & \text { goats } \\ \text { knot } & \text { toads } \\ \text { parliament } & \text { owls } \\ \text { troop } & \text { kangaroos } \\ \text { gaggle } & \text { geese } \\ \text { pride } & \text { lions } \\ \text { muster } & \text { peacocks }\end{array}$

"Although not frequently heard in conversation, these terms are fully correct and appropriate ways of describing the animal listed" (ibid.).

7. A very good illustration of values of the LF Real (and AntiReal) in English is offered in Montreal's The Gazette, Sept. 28, 1985, in a letter to Ann Landers, which we reproduce here:

Dear Ann:

I discovered this item stuck in an old book.

It was written in longhand and there is no sign of an author. I hope you will print it.

I found it highly inspirational.

$$
\text { - T. D. }
$$

Dear T.D.:

So did I. Here it is:

\section{What is life?}

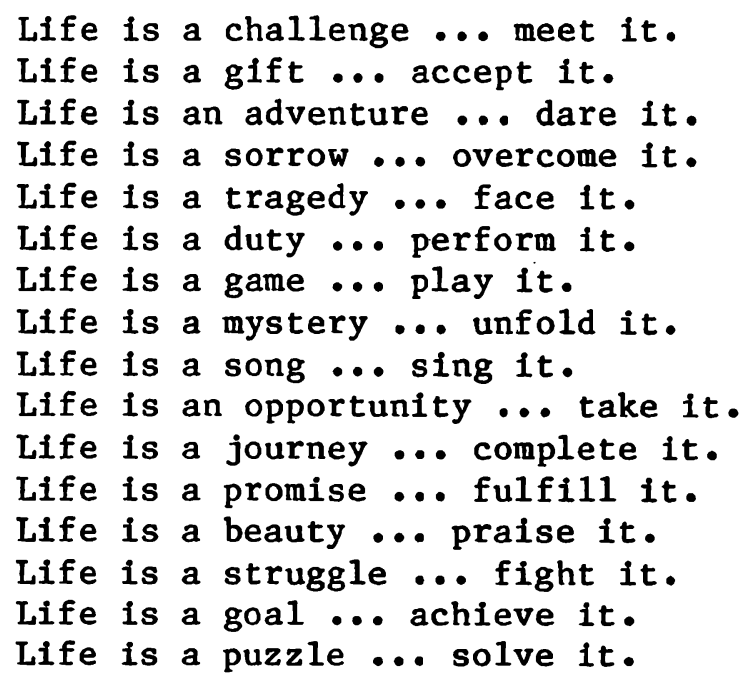

\section{References}

Bloomfleld, Leonard. 1933. Language. New York: Holt. 
Chomsky, Noam. 1966. Topics in the theory of generative grammar. The Hague-Paris: Mouton.

- 1968. Language and mind. New York etc.: Harcourt, Brace and Jovanovich.

Lakoff, Robin. 1973. Lexicography and generative grammar. II: context and connotation in the dictionary. In: R. I. McDavid and A. R. Duckert (eds.), Lexicography in English [Annals of the New York Academy of Sciences, 211], New York, 154-164.

Lamb, Sydney. 1966. Outline of Stratificational Grammar. Washington: Georgetown University Press.

Mel'Cuk, Igor A. 1981. Meaning-Text Mode1s: A Recent Trend in Soviet Linguistics. Annual Review of Anthropology, 10, 27-62.

, with Nadia Arbatchevsky-Jumarie; Léo Elnitsky; Lidija Iordanskaja; and Adèle Lessard. 1984. Dictionnaire explicatif et combinatoire du français contemporain. Recherches lexico-sémantiques I. Montréal: Les Presses de 1'Université de Montréal.

and Zholkovsky, Alexander K. 1984. Tolkovo-kombinatornyj slovar' sovremennogo russkogo jazyka. Opyty semantiko-sintaksiCeskogo opisanija russkoj leksiki [Explanatory combinatorial dictionary of modern russian]. Vienna: Wiener Slawistischer Almanach.

Nakhimovsky, Alexander. 1983. Meaning-text linguistics and the problem of voice. Carbondale-Edmonton: Linguistic Research.

Sanders, Gerald A. 1972. Equational grammar. The Hague-Paris: Mouton.

Sgall, Petr. 1967. Generativní popis jazyka a Cezká deklinace. Praha: Academia.

Testen, David; Veena Mishra; and Joseph Drogo (eds.) 1984. Papers from the parasession on lexical semantics. Chicago: Chicago Linguistic Society.

Wierzbicka, Anna. 1972. Semantic Primitives. Frankfurt/M.: Athenäum.

- 1980. Lingua Mentalis: The Semantics of Natural Language. Sydney etc.: Academic Press.

Žolkovskij, Aleksandr K., and Igor A. Mel'Zuk. 1965. 0 vozmožnom metode $i$ instrumentax semanti Instruments for Semantic Synthesis (of Texts)]. Naurno-texnireskaja informacija, No 6, 23-28. 